University of Rhode Island

DigitalCommons@URI

Open Access Master's Theses

1980

\title{
Some aspects of formulation and optimization of tablet disintegrants in direct compression systems
}

\author{
Edward M. Rudnic \\ University of Rhode Island
}

Follow this and additional works at: https://digitalcommons.uri.edu/theses

\section{Recommended Citation}

Rudnic, Edward M., "Some aspects of formulation and optimization of tablet disintegrants in direct compression systems" (1980). Open Access Master's Theses. Paper 223.

https://digitalcommons.uri.edu/theses/223

This Thesis is brought to you for free and open access by DigitalCommons@URI. It has been accepted for inclusion in Open Access Master's Theses by an authorized administrator of DigitalCommons@URI. For more information, please contact digitalcommons-group@uri.edu. 
SOME ASPECTS OF FORMULATION AND OPTIMIZATION

OF TABLET DISINTEGRANTS IN DIRECT COMPRESSION SYSTEMS

BY

EDWARD M. RUDNIC

A THESIS SUBMITTED IN PARTIAL FULFILLMENT OF THE REQUIREMENTS FOR THE DEGREE OF

MASTER OF SCIENCE

IN

PHARMACY

UNIVERSITY OF RHODE ISLAND

1980 
MASTER OF SCIENCE THESIS

OF

EDWARD M. RUNIC

Approved:

Thesis Committee

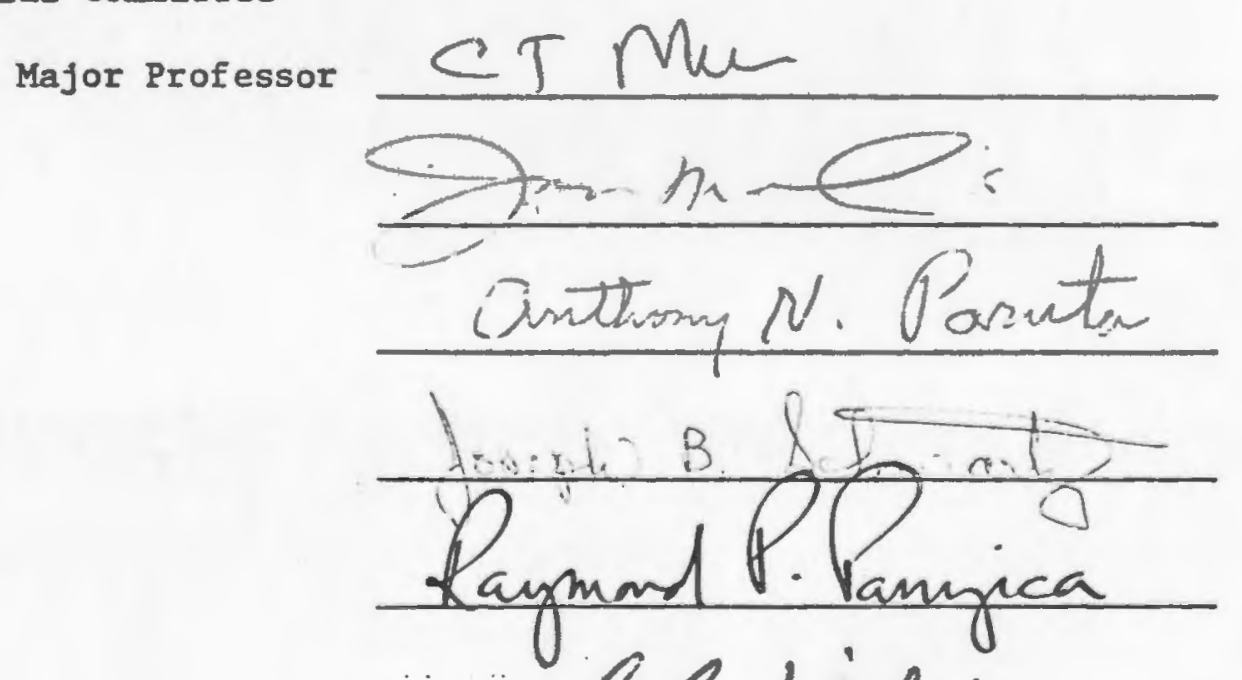

- R. Q. nobel

Dean of the Graduate School

UNIVERSITY OF RHODE ISLAND

1980 
TABLE OF CONTENTS

Page

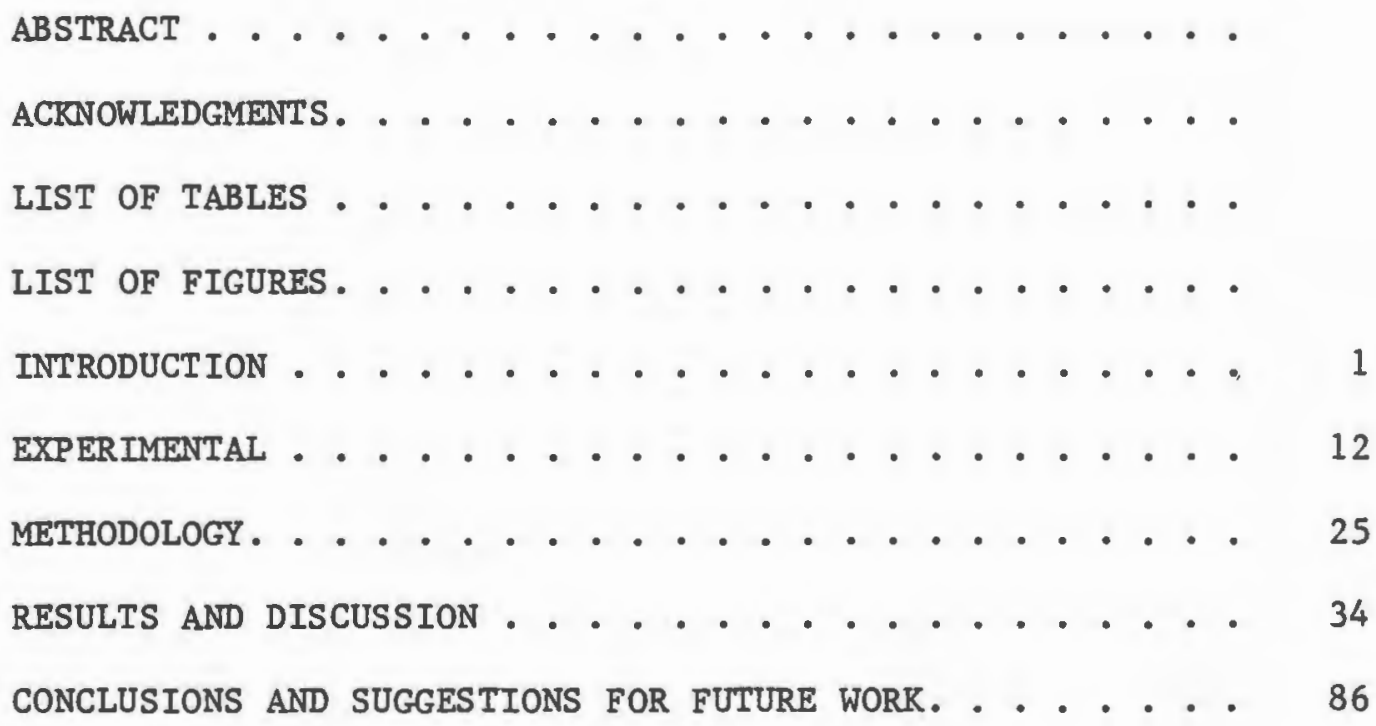

REFERENCES ................... . . 9 90

BIBLIOGRAPHY . . . . . . . . . . . . . . .

APPENDIX I. COMPUTER PROGRAM FOR STATISTICAL EVALUATION

OF DATA . . . . . . . . . . . . .

APPENDIX II. COMPUTER PROGRAM FOR CORRECTION OF

DISSOLUTION DATA. . . . . . . . . . .

APPENDIX III. STEPWISE REGRESSION ANALYSIS OF COMPACTION

DATA. . . . . . . . . . . . . . 


\section{ACKNOWLEDGMENTS}

The suggestions and assistance provided by the faculty members of the College of Pharmacy, University of Rhode Island, are gratefully acknowledged. I would especlally like to thank Dr. George E. Osborne for his interest, encouragement and editorlal comments during this profect. A special debt of sincere gratitude is due Dr. Christopher T. Rhodes for his unceasing efforts of guidance and support throughout my graduate study.

Acknowledgment is also made to Merck, Sharp and Dohme Research Laboratories, West·Point, Pennsylvania, for the opportunity to work as a research, assoclate during the perlod of June to August, 1978. Special thanks is due Dr. Joseph B. Schwartz for his guidance, both in Pennsylvania and in Rhode Island.

I also wish to acknowledge the help of Rao N. Chilamkurty for his technical assistance, R. Scott McKenzle for his editorial comments, and Beth Richardson for her warmth, personal support and friendship. 


\section{LIST OF TABLES}

I. Commonly Used Tablet Disintegrants .......... 7

II. Some Formulation and Processing Factors and the Responses Dependent on Them. . . . . . . . . . 10

III. Control Data: Density \& Sieve Analysis of Exclplents Prior to Compaction........... 35

IV. Calcium Phosphate Slow Roller Compactor Profile. . . .36

V. Calcium Phosphate Fast Roller Compactor Prof1le. . . . 37

VI. Lactose Slow Roller Compactor Proflle. . . . . . . .39

VII. Lactose Fast Roller Compactor Profile. . . . . . . .40

VIII. Calclum Phosphate/Lactose $(1: 1)$ Slow Roller Compactor Profile. . . . . . . . . . . . 42

IX. Calctum Phosphate/Lactose $(1: 1)$ Fast Roller Compactor Profile. . . . . . . . . . . . 43

X. Physical Properties of Tablets Made from Compacted Formulations (Calcium Phosphate, Lactose). . . . . .45

XI. Physical Properties of Tablets Made from Formulations with Increasing Amounts of Starch Added . .49

XII. Physical Properties of Tablets Made from Formulations with Increasing Amounts of Starch Added . .51

XIII. Physical Properties of Tablets Made from Formulations with Increasing Amounts of Starch Added . .52

XIV. Amberlite IRP-88 Concentration Profile ....... . 55

XV. CLD Concentration Profile...............56

XVI. AC-DI-SOL Concentration Proflle. . . . . . . . .57

XVII. Explotab Concentration Profile........... . 58 
XVIII. Polyplasdone XL Concentration Profile. . . . . . . 59

XIX. Corn Starch U.S.P. Concentration Profile . . . . . . 60

XX. STA-RX 1500 Starch Concentration Profile ....... . 61

XXI. Guar Gum Concentration Profile . . . . . . . . . 62

XXII. Flow Properties of Three Matrices Containing 2\%. (W/W)

P.V.P.P. in Three Particle Size Ranges . . . . . . .65

XXIII. Properties of Tablets Made with 30\% A.S.A. in

Emcompress and 2\% P.V.P.P. In Three Particle

Size Ranges. . . . . . . . . . . . . . . 66

XXIV. Properties of Tablets Made with 30\% A.S.A. in Avicel PH-101 and 2\% P.V.P.P. In Three Particle

Size Ranges. . . . . . . . . . . . . . . 67

XXV. Properties of Tablets Made with $30 \%$ A.S.A. In Avicel PH-102 and 2\% P.V.P.P. In Three Particle Size Ranges...................68

XXVI. Effect of Increasing Amounts of P.V.P.P. ("C") on Flow Properties of Emcompress. . . . . . . . . .76

XXVII. Tablet Data for Pyridoxine $\left(B_{6}\right)$ Formulation. . . . . .83 
1. Schematic Diagram of the Disintegration Process..... 3

2. The U.S.P. Disintegration Apparatus, In Use. ..... 17

3. Recording Powder Flowneter .............20

4. Three Linear Flowgraph Tracings. . . . . . . . . 22

5. Three Nonlinear Flowgraph Tracings ...........23

6. Mechanics of the Alexanderwerk Compactor ........26

7. Change in Disintegration Time as Percent Lactose in Calctum Phosphate Dihydrate Increases in the Compacted System.. . . . . . . . . . . . 46

8. Change in Disintegration Time as Disintegrant Leve1 and Method of Incorporation are Altered. . . . . . .54

9. Aspirin Dissolution Curves for the Three Grades of P.V.P.P. Used in the Emcompress Formulation. . . . . .70

10. Aspirin Dissolution Curves for the Three Grades of P.V.P.P. Using in the Avicel PH-101 Formulation. . . .71

11. Aspirin Dissolution Curves for the Three Grades of P.V.P.P. Used in the Avicel PH-102 Formulation . . . . 72

12. Change in Tablet Weight as Percent P.V.P.P. Increases in a Multivitamin Formulation. . . . . . . . .74

13. Change in Tablet Thickness as Percent P.V.P.P. Increases in a Multivitamin Formulation. . . . . . 75

14. Change in Tablet Hardness as Percent P.V.P.P. Increases in a Multivitamin Formulation. . . . . . . .77

15. Change in Friability as Percent P.V.P.P. Increases . . .78

16. Change in Disintegration Time as Percent P.V.P.P. Increases. . . . . . . . . . . . . . 80

17. Dissolution Curves for Two Levels of Grade "C" P.V.P.P. Used in an Aspirin/Emcompress Formulation . . .81 
18. Three Replicate Dissolution Curves for the Aspirin/ Emcompress Formulation Tablets. . . . . . . . . .82

19. Three Dissolution Curves for Pyridoxine Formulation Tablets . . . . . . . . . . . . . . 84 


\section{INTRODUCTION}

Because the rate and extent of drug release from a particular pharmaceutical dose form can affect the rate and extent of pharmacologic response (i.e., biological availability), there has developed over the past twenty or so years, a concern with the production of pharmaceutical products that will release drugs more efficiently. To this end, researchers have placed increasing emphasis on the disintegration of solid dosage forms, notably compressed tablets.

Absorption of a drug administered in an intact solid dose form (such as a tablet) follows a fairly well-defined sequence of events, and research has focused on examination of the factors affecting the several steps in this sequence. Since most drugs are weak electrolytes and lipophilic in nature, the time required to cross blological membranes is relatively short. However, the rate-limiting step in the absorption process for many drugs is dissolution; the drug must be in solution in order to, cross the blological membrane. In turn, the rate-limiting step in the dissolution of drugs from solid dosage forms is commonly disintegration. When a tablet breaks up into many smaller particles, the surface area exposed to the solvent media is greatly increased. To illustrate this point, if a flat-edged (cylindrical) tablet with a thickness of one millimeter and diameter of three mfllimeters breaks up into perfect spheres just small enough to pass through the mesh in the U.S.P. Disintegration Apparatus, the 
increase in surface area would be on the order of $10^{2}$. This extremely simplistic view of the disintegration process suffers from the fact that the size of particles often will be smaller than those described above, and so the value is greatly underestimated. As surface area is increased, dissolution efficlency is also increased. This concept is shown schematically in Fig. 1.

Most of the research on the disintegration of solid dosage forms has occurred in recent years, although it is not solely a contemporary activity. Indeed, over a century ago a U.S. Patent recommended perforation of pills so enhanced penetration of gastric fluid would result in faster disintegration ( 1 ). In more recent times researchers have agreed that tablet disintegration is an extremely important parameter in formulating solid dosage forms (2-13), and many substances have been tested for their ability to accelerate the disintegration process (14-31). A comprehensive list of these agents was compiled by Lowenthal (2).

To explain the mechanisms by which these disintegrants act, several theories have been postulated. Matsumaru (23) proposed that the heat of wetting of the disintegrants caused entrapped air in the tablet to expand, and thus produced disintegration. Krowczynski, et al. (24), theorized that an increase in the rate of disintegration was due to the formation of a larger system of capillaries by virtue of smaller particle sizes of starch. Jaminet, et al. (25) suggested that the disintegration process is dependent upon the solubility of the ingredients in the formulation. They reported that the rates of disintegration were related to the 


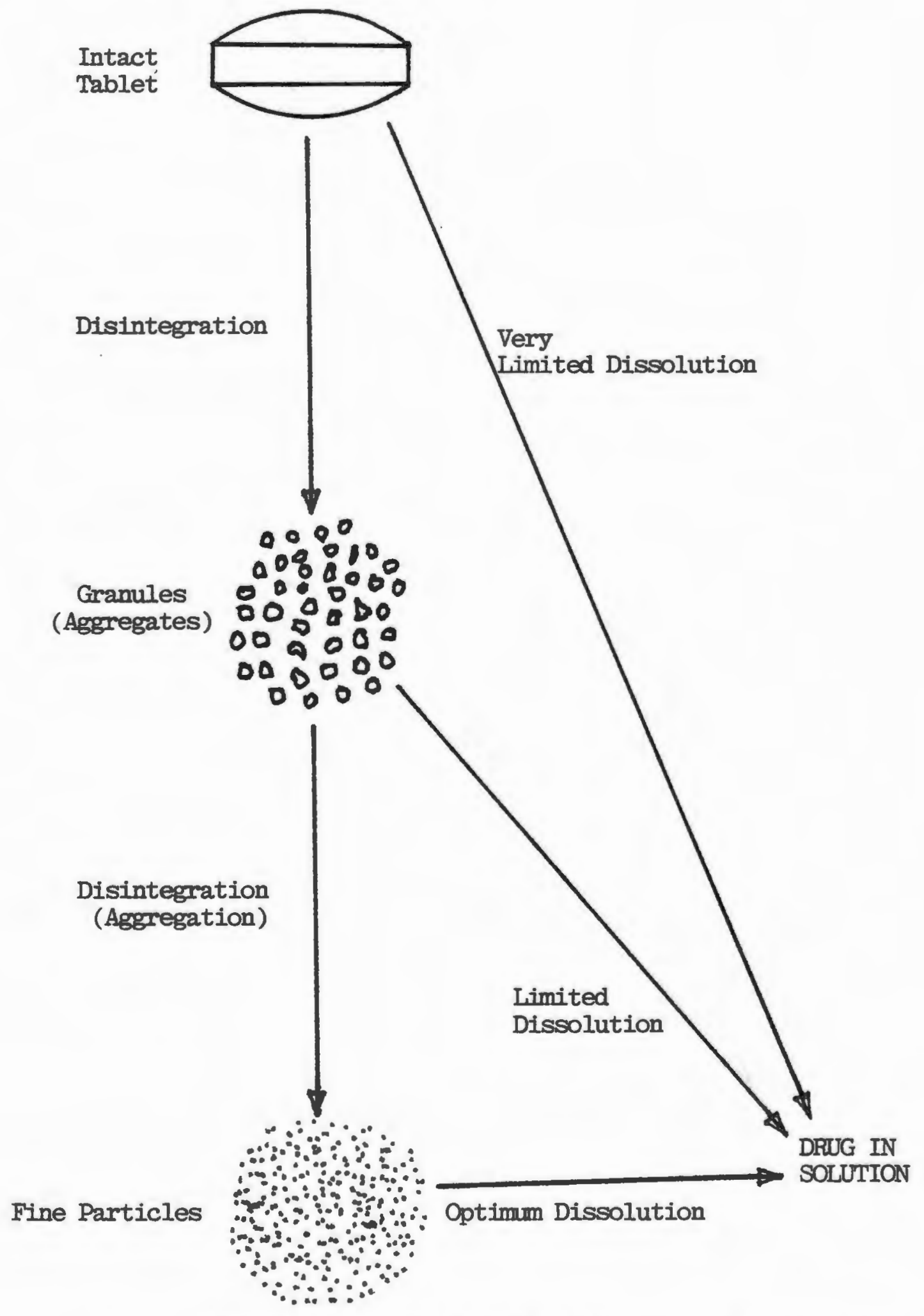

Fig. -Schematic Diagram of the Disintegration Process. 
rate of liquid penetration into the tablet. Another theory of tablet disintegration is concerned with disintegrant swelling. The occurrence of swelling of disintegrants has been extensively observed (24-30). It has been postulated that tablets made with a low compressional force, giving a high tablet porosity, did not have proper resistance to the swelling actions of the disintegrant; the result is a high disintegration time. Tablets made with a high compressional force, giving a low tablet porosity, did not allow enough fluid to enter the tablet and come in contact with the disintegrant; thus the disintegration time was again elevated. Tablets made with a moderate compressional force, gave a medium porosity, allowed a sufficient amount of fluid to penetrate the tablet, offered an optimum of resistance, and resulted in low disintegration times $(30,31)$. There have been numerous studies to support this relationship between the applied force of compression of the tablets and resultant disintegration time $(68-75)$.

Although there is some disagreement about which model best explains the action of tablet disintegration, it should be realized that the mechanism of action of any given disintegrant w1ll probably be the resultant of any or all of these mechanisms, or even others that have yet to be studied. The disintegration process, by any mechanism, follows a specific sequence: tablet disintegration, followed by granule disintegration (aggregation). The process of making this sequence more efficient is termed "optimization," which is defined as "an effort to achieve the best or more favorable condition for a particular situation (64)." 
Optimization of disintegration in pharmaceutical systems is controlled by both formulation factors and processing factors. We can select the types and/or concentrations of the various ingredients in a formulation; and we can modify processing factors such as compresstonal force.

Although there are published reports where attempts were made to optimize disintegration by altering the nature or concentration of disintegrant $(32-35)$, or by controlling process varlables $(3,7,18,36-40$, $48,49)$, there does not appear to be many published studles where attempts were made to optimize disintegration by altering the particle size of the disintegrant. Further, to date there have been few published studies concerning the use of intra- and extragranular disintegrant in pre-compression formulations.

Investigators have shown that tablet matrices, for use in non-granulated formulations, can be produced by pre-compression (45-47), and it therefore seems plausible that this method could be used to manufacture exclpient systems with intra- and extragranular disintegrants. In addition, by varying the process variables used in the pre-compression stage, it seems probable that the effects of such variables on disintegration may be demonstrated.

Once a working knowledge of the many process variables and their effects on the disintegration process has been obtained for a given system, it would be possible to optimize the function of the disintegrant in that system.

The first consideration when choosing a tablet disintegrant should be the relative efficiency of commercially available disintegrants in 
the system desired. This should be done by keeping all of the process varlables constant during tableting, so that the effect of the Individual disintegrant is the only factor tested. A brief list of commercially available disintegrants was compiled (37) and appears in Table I. Because these substances, especilly the newer products, have been shown to be effective in very low concentrations, they should be evaluated in even lower concentrations, in order to discern their relative efficiency.

The selection process should consist of evaluating both the physical and chemical (if any) actions of the various disintegrants. Availability of these substances and ease of processing should also be considered. Once a specific tablet disintegrant has been chosen, It would then be advisable to optimize its function within a given system.

There have been numerous investigations into the effect of altering the method of disintegrant incorporation on the disintegration time of tablets $(24,51-57)$. Thus by altering the method of Incorporation, with all other variables constant, an optimum procedure for processing could be obtained.

It has been generally recognized that disintegration time will usually decrease as the disintegrant concentration increases (14-31, 76-78). However, in at least one study, it has been noticed that disintegration time can actually increase with increasing disintegrant concentration (79). Although an unusual case, it has been generally accepted that very high concentrations of tablet disintegrant can cause untoward effects in processing of the tablet (80-82). 
Table I

Cormonly Used Tạblet Disintegrants *

Substance
STARCHES
MODIFIED STARCHES
MICROCRYSTALLINE
CELLULOSES
CEILULOSE DERIVATIVES
(WATER SOLUBLE)

(WATER SOLUBLE)

SODIUM ALGINATE

CLAYS

ALGINIC ACID

GUMS

POLYVINYLPOLYPYRROLIDONE(PVPP)

ION EXCHANGE RESINS

SPECIAL CELLULOSE DERIVATIVES
Types/Brands

Corn, maize, potato rice.

Corm starch is most commonly used.

Sodium carboxymethyl starch (Explotab or Primogel).

Avicel PH-101 and Avicel PH-102, Avicel RC-591

Methyl Cellulose, Sodium carboxymethyl cellulose, Hydroxypropyl methyl cellulose.

Landalgine

Veegum

Guar gum

Polyplasdone XL Kollidon CE5050

Amberlite IRP-88

Ac-Di-Sol, CLD
Concentration/Method

$5-10 \%$ to dry granulation

$1-8 \%$

$5-15 \%$

Wet granulation or direct Compression.

5-10\%

Wet granulation or direct compression.

2-5\%

Wet granulation or direct compression.

$5-10 \%$

Wet granulation or direct compression.

5-10\%

Wet granulation or direct compression.

$5-15 \%$

Wet granulation or direct compression.

$0.5-5 \%$

Wet granulation or direct compression.

$0.5-5 \%$

Direct compression.

$0.5-5 \%$

Wet granulation or direct compression.

* Adapted from 'Problem Solver", (37), p 
It has been suggested that many formulators employ an "overkill" approach when formulating tablet disintegrants, thereby allowing their product to be more susceptible to the adverse effects of disintegrants.

In addition, although the chemical nature of a disintegrant may be known, very few formulators know how the physical nature of the disintegrant relates to disintegrant action. The changes that occur in drug absorption when particle size is altered has been studied (58-63); however, the effect of varying particle size of tablet disintegrants has yet to be conclusively delineated $(7,24)$. Thus, particle size, as well as other physico-chemical properties of the disintegrant should be considered to optimize the disintegrant and its function with in the pharmaceutical system. Therefore, when considering a pharmaceutical system that must disintegrate, the effects of processing, procedure, formulation components and the disintegrant's chemical and physical properties should be defined and evaluated.

Because the dosage form is expected to conform to certain guidelines with respect to the disintegration time, it should be noted that any variation in either the disintegration apparatus of the procedure used (see methodology section) may cause a variation in results of any disintegration test. Thus the testing procedure should remain constant throughout the study, in order to assure minimum testing error. 
In addition, the tablet must also conform to tests other than disintegration. There are many responses by the tablet to changes in the formulation and processing of the dose form. These responses and variables responsible for them are shown in Table II. The likelthood of arriving at a formulation and procedure that w111 achieve an optimum for all of the response variables is small. The formulator may be forced to reach a compromise between all of the vartables and select a formulation and procedure that may not be best for any given response, but that w1ll be the best compromise for all responses. This is the basic princlple associated with any optimization procedure involving more than one varfable.

The first objective of this thesis is to study some of the process variables involved when disintegrants are incorporated into pre-compression systems, and to determine their effect on the disintegration process. Using a chilsonator/mill and varying the operating conditions, should make possible the achievement of this goal.

The second objective of the study concerns the selection of an appropriate disintegrant by evaluating several tablet disintegrants at a low concentration and keeping the process vartables constant. Finally, the thesis will be concerned with the selection and subsequent optimization of one tablet disintegrant. It was thought important to study one disintegrant in depth, rather than superficially study many disintegrants in this phase of the thesis. The effect of altering the particle size and concentration of the disintegrant will be related to parameters such as disintegration and dissolution times of a number of drugs. 
SOME FORMULATION AND PROCESSING FACTORS AND THE RESPONSES DEPENDENT ON THEM

FORMULATION VARIABLES

1. Diluent Ratio

2. Compressional Force

3. Disintegrant Level

4. Binder Level

5. Lubricant Level

PROCESS CONSTANIS

1. Granulating Conditions

2. Milling Conditions

3. Drying Conditions

4. Dry Blending Equipment and Times of Blending

5. Compressing Machine Speed
RESPONSE VARIABLES

1. Tablet Disintegration

2. Tablet Hardness

3. Drug Dissolution

4. Tablet Friability

5. Weight Uniformity

6. Tablet Thickness Uniformity

7. Tablet Porosity (Pore Volume)

8. Mean Pore Diameter

9. Tablet Appearance

10. Mean Granule Diameter

* Adapted from (40), J. B. Schwartz, et al. 
By examining process variables, relative disintegrating efficiency of common disintegrants, and the effect of altering physico-chemical properties of a tablet disintegrant, it should then be possible to shed some light on the optimization process when applied to tablet disintegrants in general. 


\section{EXPERIMENTAL}

\section{A. Material:}

1. Drugs - The drugs used in this study were avallable commercially. Acetylsalicylic Acid (Aspirin) ${ }^{1}$ (1os X2729531)

Ascorbic Acid (Vitamin C) ${ }^{2}$ (lot 328956)

Nlacin ${ }^{3}$ (lot 52080)

Pyridoxine (Vitamin $\left.B_{6}\right)^{4}$ (lot 6878)

Riboflavin (Vitamin $\left.B_{2}\right)^{5}$ (lot P1964)

2. Disintegrants - The tablet disintegrants used were available comercially. The disintegrants with the letters "M.S.D." before the lot and code numbers were provided by Merck Sharp and Dohme. Those disintegrants with the words "pilot batch" in place of the lot numbers were special adaptations of commercially available disintegrants, supplied especially for experimental purposes and were supplied by the manufacturer.

\footnotetext{
${ }^{1}$ Ruger Chemical Co., Irvington, New Jersey.

${ }^{2}$ J. T. Baker Chemical Co., Phillipsburg, New Jersey.

${ }^{3}$ Merck and Co., Rahway, New Jersey.

${ }^{4}$ Nutritional Biochemicals Co., Cleveland, Ohio. ${ }^{5}$ Mann Research Laboratories, New York, New York.
} 


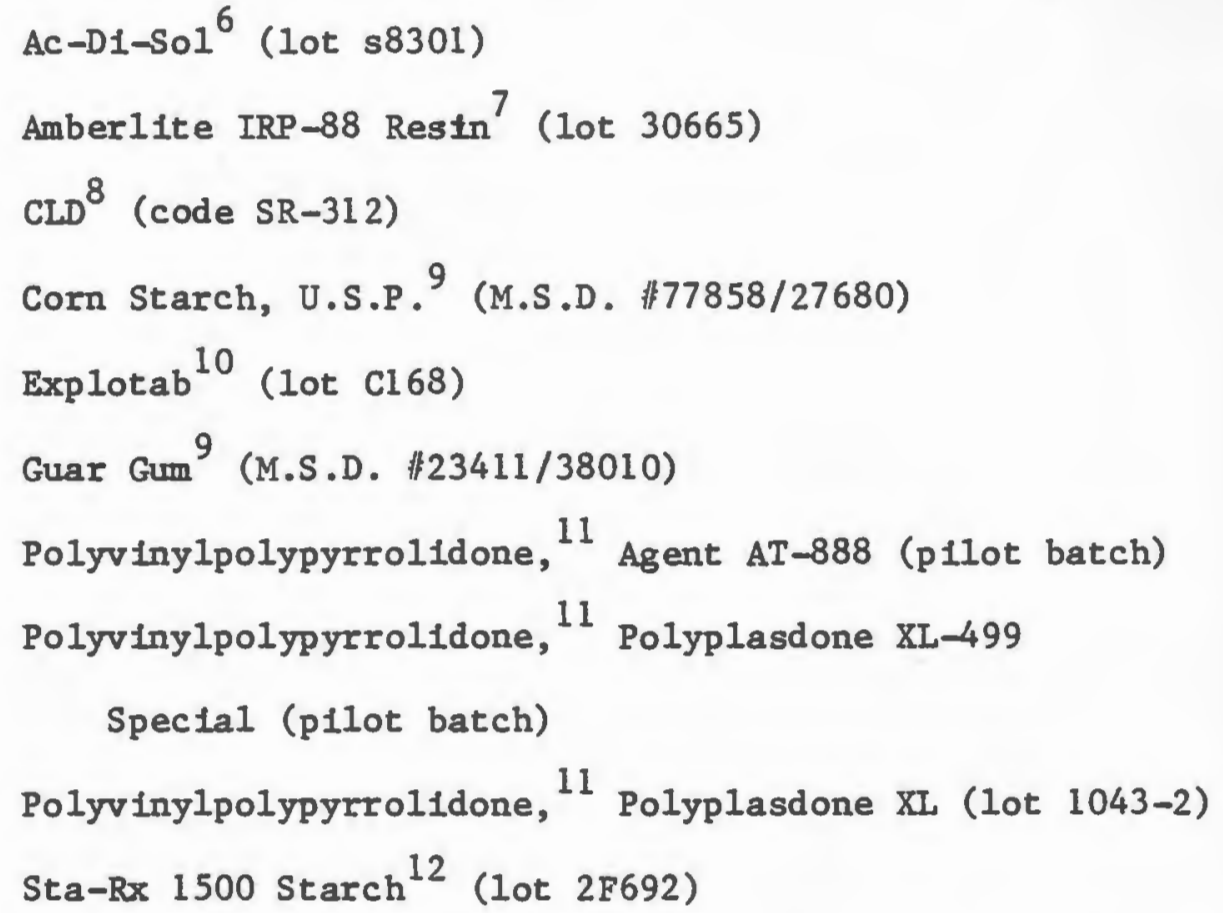

3. Exclpients - the exciplents used in this study were available commerclally. Those exciplents with the letters "M.S.D." before the lot and the code numbers were provided by Merck Sharp and Dohme.

${ }^{6}$ FMS Corporation, Philadelphia, Pennsylvania.

${ }^{7}$ Rohm and Haas Co., Philadelphia, Pennsylvania.

8 Buckeye Corp., Memphis, Tennessee.

${ }^{9}$ Merck Sharp and Dohme Research Laboratorles, West Point, Pennsylvanla. 10 Edward Mendell Co., Carmel, New York.

${ }^{11}$ GAF Corporation, LInden, New Jersey. ${ }^{12}$ Staley Starch Co., Decatur, Illinois. 
Avicel $\mathrm{PH}-101^{13}$ (lot $1852-3616$ )

Avicel PH-102 13 (lot $7701-790$ )

Dibasic Calcium Phosphate Dihydrate (Unmilled) 14

(M.S.D. \#84333/24010)

Dibasic Calcium Phosphate Dihydrate (Milled) 14

(M.S.D. \#84874/21490)

Lactose (Anhydrous) ${ }^{14}$ (M.S.D. \#561133-00J03, ND11-45)

Lactose (Hydrous) ${ }^{14}$ (M.S.D. \#84333/24010)

4. Lubricant - The lubricant throughout the study remained constant, although the lot numbers were different. Magnesium Stearate ${ }^{14,15}$ (M.S.D. 非6340/24270) (Code N49483)

5. Equipment - The following equipment was used for the analytical procedures, compaction, tableting, and subsequent analysis of physical parameters.

Colton Model $216^{16}$ Rotary Tablet Press

Erweka Hardness Tester, ${ }^{17}$ Type TBT (Nr19306)

Erweka Tap-Abrasion Tester ${ }^{17}$ (code 1AP)

${ }^{13}$ FMC Corporation, Philadelphia, Pennsylvania.

${ }^{14}$ Merck, Sharp and Dohme Research Labs., West Point, Pennsylvania.

${ }^{15}$ Ruger Chemical Co., Irvington, New Jersey.

${ }^{16}$ Colton Machine Co., Detroit, Michigan.

17 Erweka Apparatebau, West Germany. 
Hewlett-Packard Desk Top Calculator ${ }^{18}$ (Model 10) and Plotter (Model 9862A)

Hot Plate ${ }^{19}$ (Model PC-35)

Single Pen Strip Chart Recorder 20

Mettler Balance (Model H8) 21

Mettler Balance (Model PR1200) 21

Alexanderwerk Compactor 22

\section{B. Physical Tests:}

The physical tests (excluding powder flow) were performed on the tablets produced during the various phases of this study. They are as follows:

1. Weight - The weight of each individual tablet was determined by dusting each tablet off with a camel hair brush, and placing it on an electronic balance. This procedure was repeated for ten tablets (In certain cases, it was thought necessary to repeat the procedure more than ten times). The data from the tablets was then analyzed for sample mean and Relative Standard Deviation (R.S.D.). This procedure is explained in part "E" of this section. The R.S.D. value was used as a measure of weight variation within a sample of tablets.

${ }^{18}$ Hewlett-Packard Co., Loveland, Colorado.

${ }^{19}$ Corning Glass Works, Corning, New York.

${ }^{20}$ Linear Instrument Co.

${ }^{21}$ Mettler Instrument Corporation, Princeton, New Jersey.

${ }^{22}$ Alexanderwerk, Switzerland. 
2. Thickness - The thickness of ten tablets was determined by first dusting of the surface of the tablet with a brush, and then placing it in the jaws of a micrometer. The measurements were recorded and analyzed for mean value and R.S.D. as a measure of variation.

3. Hardness - The hardness of ten tablets was determined by placing each tablet in an electronic hardness tester (Erweka) which recorded the breaking strength of the tablet in kilograms. This procedure was repeated ten times, and the data was analyzed for sample mean and R.S.D., as a measure of variation.

4. Friability - This test is a measure of abrasion resistance and was determined by first weighing twenty tablets after dusting, placing them in a tumbling chamber with plastic baffles, and rotating the basket vertically at a fixed rate for twenty minutes. The total welght of the twenty tablets (or what was left of them) was recorded, after dusting, and the percent friability was determined as follows:

Fr $=100 \times \frac{\text { Weight (original) }- \text { Welght (final) }}{\text { Welght (original) }}$

5. Disintegration - Tablet disintegration was tested by using the U.S.P. apparatus, as described in the National Formulary (10). Fig. 2 schematically illustrates how this apparatus is set up. The time needed for all the fragments to pass through the mesh at the bottom of the test cage was noticed visually, and was recorded. A mean value for six tablets was calculated and the range of values was also recorded. 


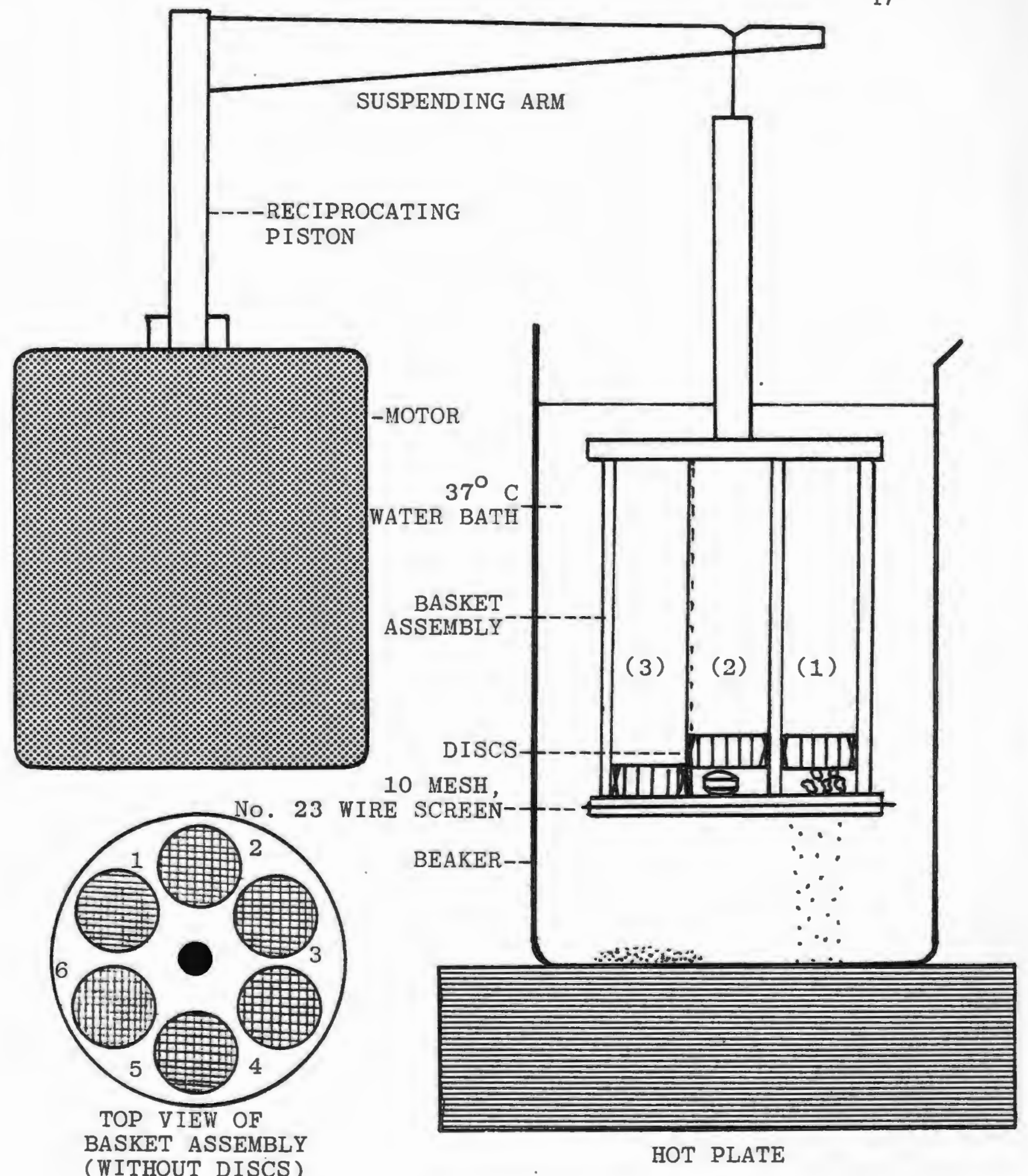

Fig. 2 -The U.S.P. Disintegration Apparatus, In Use.

(2)-no disintegration, (1)-in process of disintegration, (3)-disintegration completed. 
6. Dissolution - Drug dissolution was also performed on a U.S.P. apparatus, and according to monographs in U.S.P. XIX (97). The exact equipment used was the U.S.P. "basket" assembly, and $5 \mathrm{~m} 1$. samples were removed at times of $1 / 2,1,2,4,7,10$, and 30 minutes, or until $100 \%$ dissolution was observed. Plots of these readings were made to visually depict the dissolution process (see part "E" of this section).

\section{Analytical Procedures:}

1. Dissolution - When a drug was to be measured for rate and extent of dissolution, or content uniformity, a sample of the lot of drug to be used was run through a scanning U.V. Spectrophotometer to determine the $\lambda_{\max }$ for that particular drug. Once this value was determined, the spectrophotometer was set at this wavelength, and each sample was analyzed for absorbance at this wavelength at various concentrations; the results being recorded in a Beer's plot. The drug monograph, as It appeared in the U.S.P. XIX, was used as a reference for determining the dissolution medium for the test.

\section{Flowmeter:}

The flowmeter was used to analyze the varlous flow characteristics of the various powders used. The device consisted of a stainlesssteel powder hopper suspended over an analog balance, which in turn sent output signals to a strip-chart recorder. For 
practical purposes, the hopper, or funnel was taken from a Stokes Model F, single punch tablet press.

The apparatus was designed, as an extension of work done by Duvall and coworkers. They were hampered by the fact that convenfent analog balances were not avallable at the time of their studies. Jordan and Rhodes applied the concepts outlined by Duvall and applied them to modern equipment. The flowmeter used in this study was an improvement on the latter design, and is shown in F1g. 3 .

The recorder was calibrated such that one kilogram of weight caused a pen deflection equal to the entire scale of the chart. The chart speed was set at 30 centimeters/minute and remained constant throughout the study.

By removing the glass stop-plate, and allowing the powder to fall onto the balance pan, wich in turn results in a flowgram, or tracing. The flowgrams were then examined for time of powder flow by transforming the centimeters covered into seconds. The total weight at the top of the scale was read, and the value was divided by the number of seconds to give the mass flow rate, in grams/second. This is only a mean flow rate, and the rate may have changed during the flow process. A measure of this change is the linearity value. Since ideal flow has been thought of in linear terms, it was felt that by using a linear regression to fit the data, and analyzing the least squares correlation coefficient $\left(r^{2}\right)$ a good index of linearity could be obtained. 


\section{RECORDING POWDER FLOWMETER}

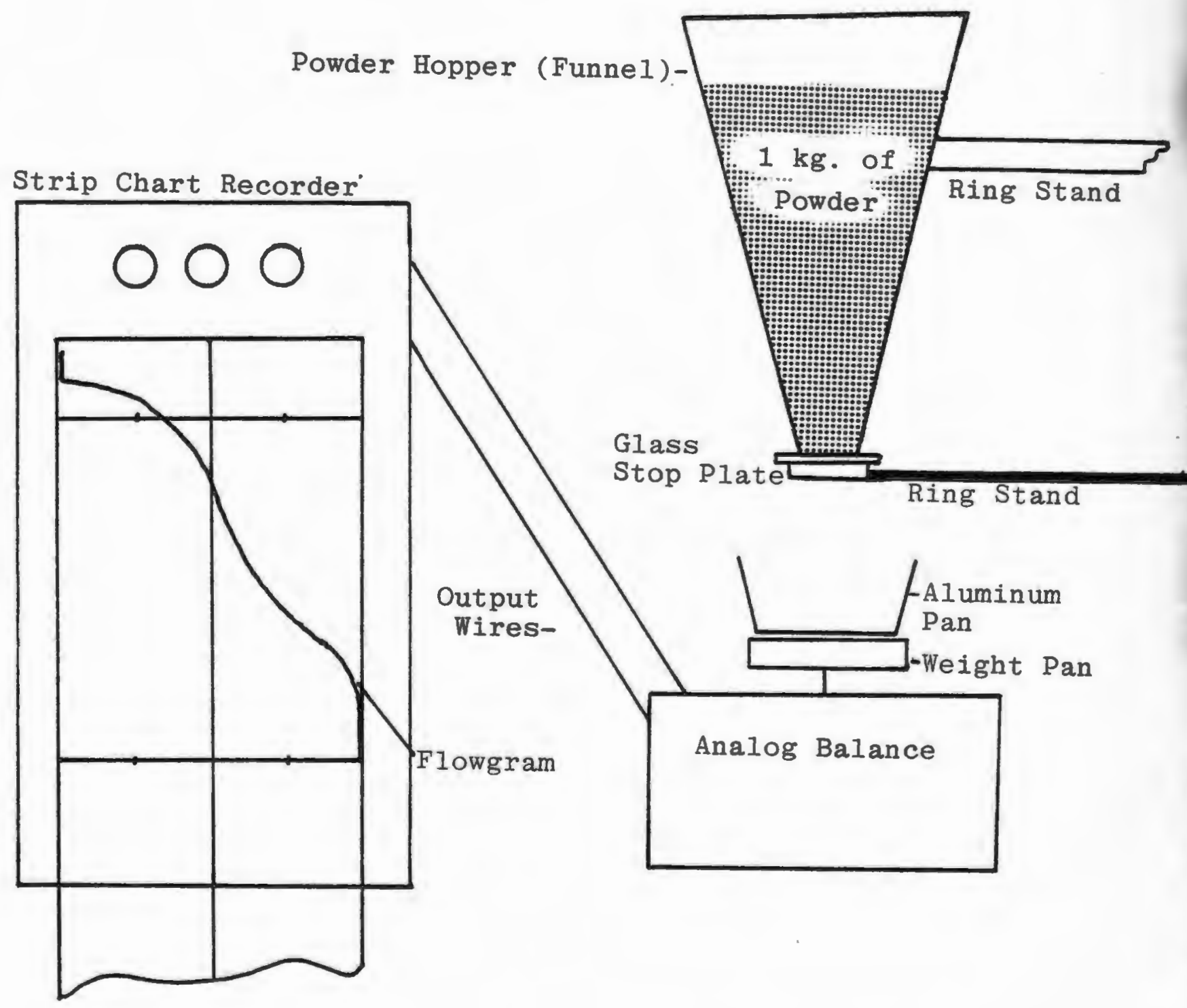


By altering the $r^{2}$ in such a way that all values below 0.8 are omitted (as these are unacceptable values) and expanding the remaining values to a scale of twenty, a workable linearity index Is achleved. Thus, the equation for the least squares correlation factor conversion is as follows:

$f 1=\left(r^{2}-0.8\right) \times 100$

where: $f 1=$ Powder Flow Index

$r^{2}=$ Least Squares Correlation Coefficient

This evaluation was carried out in three trials, and the powder flow characteristics were reported as mean values. Examples of how these numbers correspond to the flowgrams can be seen in FIg. 4 and 5 .

E. Interpretation of Data:

1. Physical Tests - The physical tests were run for ten trials on each sample set. The data from the sample set was analyzed for mean value and Relative Standard Deviation (R.S.D.). A digital computer program written in Basic was used to calculate these values, using the equation: Relative Standard Deviation $=$ R.S.D. $=\frac{S}{\bar{X}} \times 100$

Where: $S$ = standard deviation of sample $\overline{\mathrm{X}}=$ sample mean

The computer program used appears in Appendix I.

2. Dissolution - The dissolution samples (five milliliters) were not returned to the dissolution bath so that there was a 


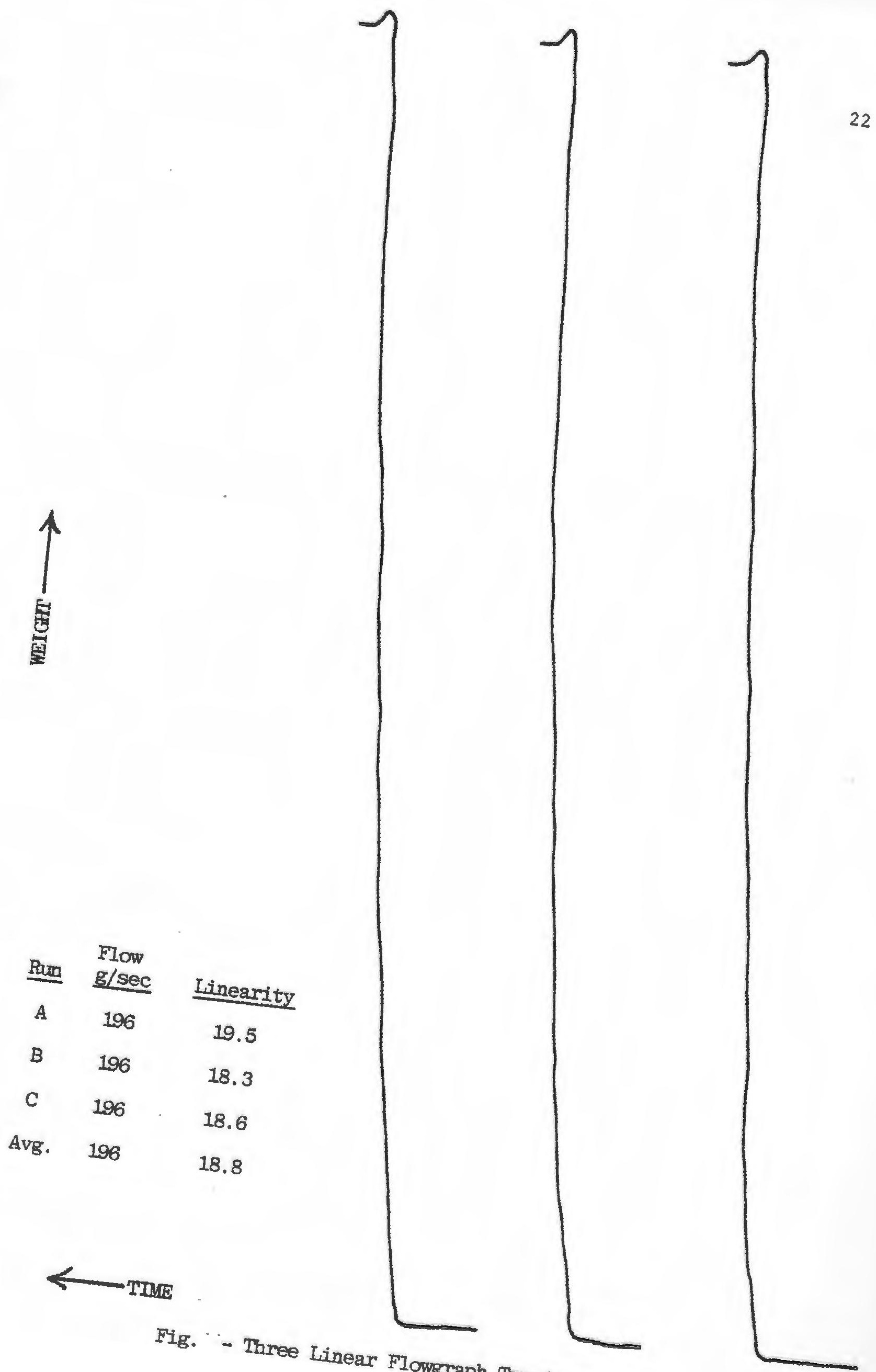




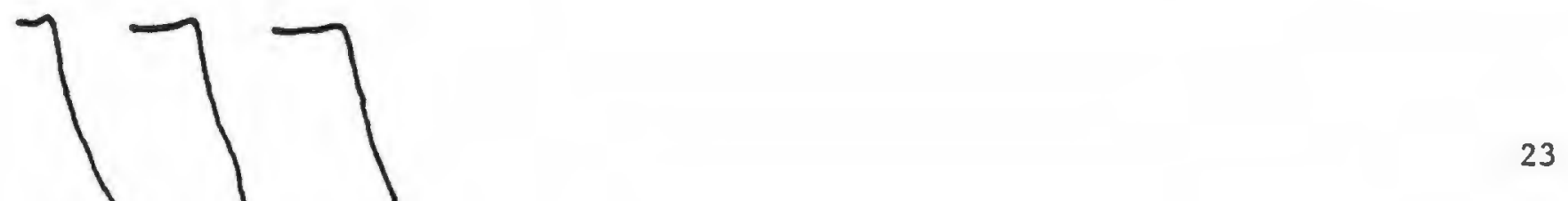



\begin{tabular}{|c|c|c|}
\hline Run & $\begin{array}{l}\text { Flow } \\
(\mathrm{g} / \mathrm{sec})\end{array}$ & Linearity \\
\hline A & 18.5 & 13.6 \\
\hline B & 19.3 & 12.4 \\
\hline C & 20.0 & 8.8 \\
\hline Avg. & 19.3 & 11.6 \\
\hline
\end{tabular}

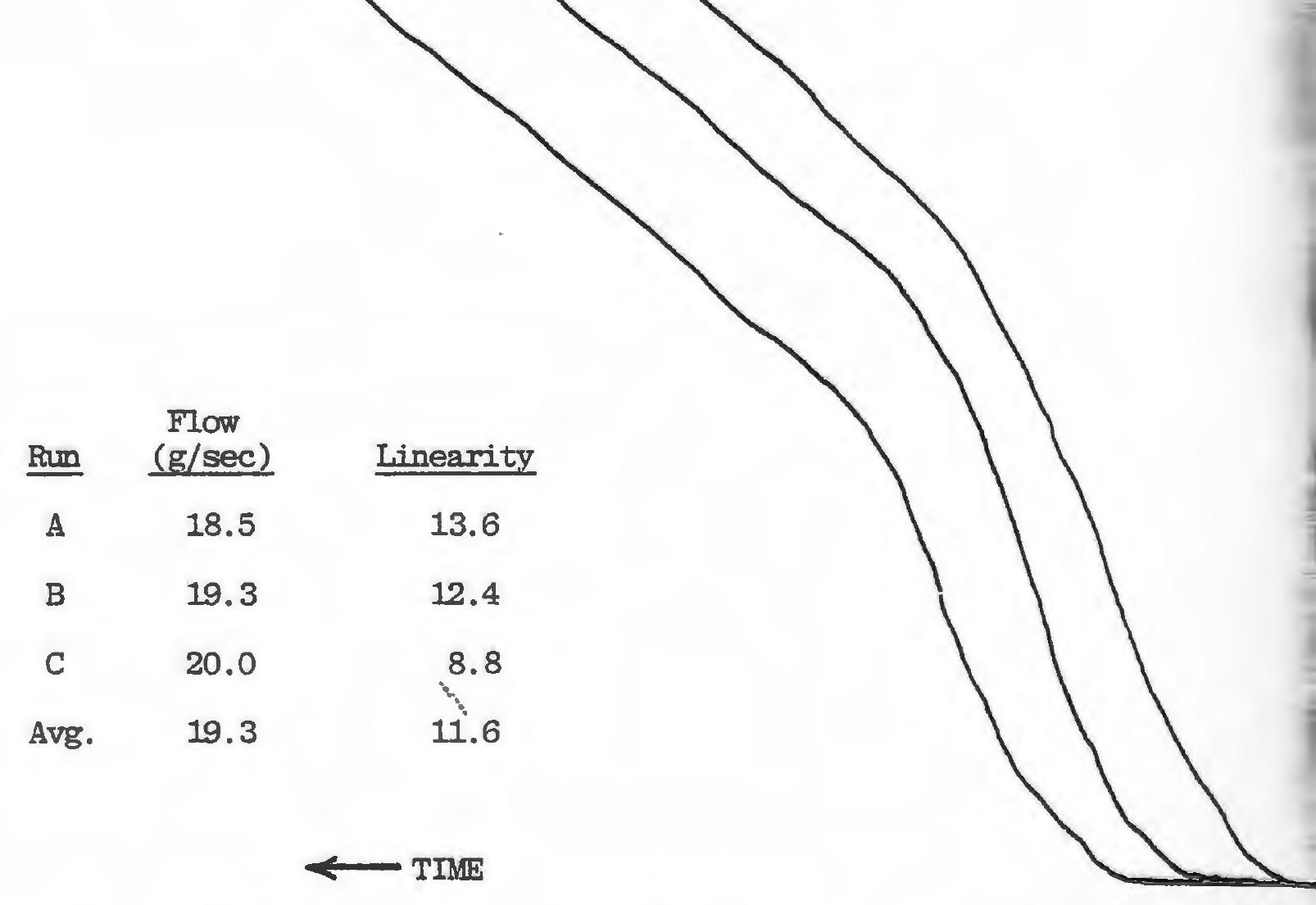


certain amount of drug being lost in each sample. This drug loss reflects on subsequent samples and thus introduces an error in procedure. This error was corrected by using a digital computer program utilizing the following equations to determine the amount of drug in the five milliliter sample:

$$
\begin{aligned}
\text { Conc }= & \frac{A-b}{m} \\
\text { Where: } A & =\text { absorbance } \\
m & =\text { slope of Beer's Plot } \\
b & =\text { intercept of Beer's Plot }
\end{aligned}
$$

The computer program appears in Appendix II. 


\section{METHODOLOGY}

\section{A. Validation of Compactor:}

Milled dibasic calcium phosphate dihydrate, hydrous lactose, and a 1:1 mixture of these two exciplents were the three systems chosen for the validation procedure. Each system was run through the compactor (see Fig. 6), while the various machine settings were altered during the granulation process. Two speeds of the compression rollers were possible, and these were designated as "slow" and "fast." The auger screw speed was continuously varlable from settings of " 0 " to "g" and four speeds were chosen: \#1 (7 r.p.m.), \#3 (15 r.p.m.), \#6 (30 r.p.m.) and \#9 (45 r.p.m.). The compactor pressure was also continuously varlable from 0-100 atmospheres (ATM) and the following compaction pressures were chosen: 30 ATM, 50 ATM, and 70 ATM. In each run, there was a \#16 screen mesh used for the mill portion of the machine.

By varying the roller speed, the dwell time, or the time that the powder was exposed to pressure was varled. By altering the auger screw speed, the amount of powder pushed between the rollers was also varied. There were certain conditions that were unfavorable, and caused a great deal of machine straln that was heard and seen. Because of this, any run that was not to be considered free of machine strain, was rejected and not included in the test study. 


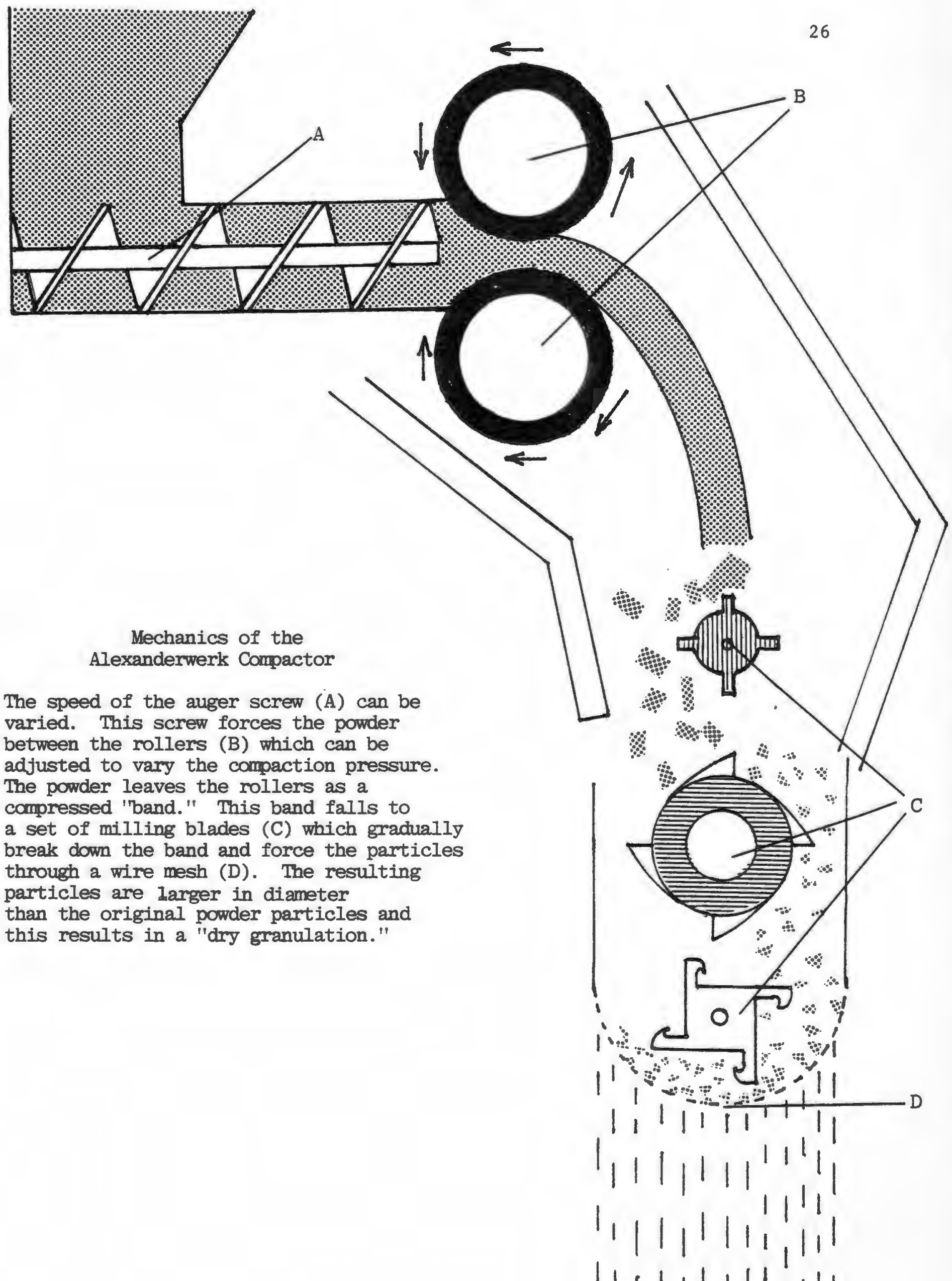


By varying all of the previously mentioned variables, it was possible to provide for 24 theoretical granulation conditions. The granulations were then subjected to a sieve analysis and bulk/tap density measurements. The sieve analysis and bulk/tap density measurements were also taken on the powders before compaction, and served as a control.

The data assoclated with this part of the study appears in Tables III-IX.

\section{B. Selection of Compacted Matrix:}

The granulations produced in part $A$ of this section were lubricated by mixing in magnesium stearate, in a $0.5 \%(\mathrm{~W} / \mathrm{W})$ concentration, in a twin-shell blender for fifteen minutes. The lubricant was passed through a 160 mesh bolting cloth before addition to the granulation as to inhibit agglomeration of magnesium stearate during the mixing process. Various physical mixtures of the already compacted matrices were prepared. The calcium phosphate and lactose were mixed in 25:75, 50:50 and 75:25 ratios. Using an instrumented Stokes Model F single punch press, the applied pressure was kept fafrly constant at 3700 pounds. The resulting tablets were then tested for weight, thickness, hardness, and disintegration time by procedures outlined previously. The data resulting from these tests appears in Table X.

\section{Starch U.S.P. Disintegration of the Compacted Materials:}

Based on the disintegration results in part $B$ of this section, calcium phosphate and lactose in a 75:25 ratio was chosen as the test 
system. Mixtures for this segment of the study were prepared in three different ways. Dibasic calclum phosphate dihydrate and hydrous lactose were compacted under conditions determined in part A of this section: 50 ATM pressure, slow roller speed, and auger screw speed \#3. They were mixed together in a 75:25 ratio and corn starch U.S.P. was added in increasing amounts $(1 / 2 \%, 1 \%, 2 \%, 5 \%$ and $10 \%$, with a control system with no disintegrant) by mixing the ingredients in a twin shell blender for five minutes.

The same lots of calcium phosphate and lactose were then mixed In a 75:25 ratio. again, but this time were compacted together. Again the same lot of corn starch was added in increasing amounts and mixed In the same manner.

For the third test system, calcium phosphate and lactose were mixed in a $75: 25$ ratio with the various amounts of starch being added before compaction. This latter system represents the only system where starch was compacted. As with all of the previous test systems, the granulations were lubricated with $0.5 \%$ magnesium stearate, added after compaction.

The three systems were then tableted on an instrumented Stokes Model F, single punch press. An effort was made to keep the applied compressional force constant at 3700 pounds. The tablets produced were tested for weight, thickness, hardness, and disintegration time, and the data appears in Tables XI-XIII. 
D. Effects of Low Levels of Disintegrants:

After testing the effects of process variables on the disintegration process, it was of interest to examine the effects of low levels of various disintegrants in one of the systems chosen from part B of this section.

Unmilled calcium phosphate and lactose (anhydrous) were mixed in a $75: 25$ ratio in a twin-shell blender, for fifteen minutes. This mixture was then used as the excipient system throughout this part of the study, and served as the control system when no disintegrant was used. Elght tablet disintegrants were chosen: corn starch, U.S.P.; . Amberlite (IRP-88 (an ton-exchange resin); CLD (an anionic polymer of cellulose); Explotab (carboxymethyl starch derfvative); Ac-D1-Sol (modified cellulose gum); Sta-Rx 1500 Starch (pre-gelatinized starch); Polyplasdone XI (cross-Iinked polyvinylpolypyrrolıdone), and guar gum. These disintegrants were added to the system described above in concentrations of $0.25 \%, 0.5 \%, 1 \%$ and $2 \%(w / w)$ by mixing the appropriate amount of disintegrant with the excipient system and magnesium stearate at a $0.5 \%$ level, for fifteen minutes in a twin-shell blender.

Each disintegrant/excipient system and control was then tableted using the instrumented press described earlier. The applied compression force was kept constant at 3700 pounds for each formulation. The resulting tablets were then tested for welght, thickness, hardness, and disintegration.

In addition to the tableting studies, each formulation was tested for its flow properties. Each disintegrant was added to the excipient 
system in concentrations of $0.25 \%, 0.5 \%, 1 \%$ and $2 \%(w / w)$ with a control system. One kilogram of each system was then run through the recording powder flowmeter, described earlier. Each system was evaluated for mass flow and deviation from linear flow.

The tablet and flow data for each disintegrant is 11sted in Tables XIV-XXI.

\section{E. Optimization of P.V.P.P. as a Disintegrant:}

Since the effects of excipient system and concentration on disintegrant activity was examined in sections $B, C$, and D, it was felt that optimization of the disintegrant itself should be attempted. One of the disintegrants studied in part $D$ of this section, polyvinglpolypyrrolidone (P.V.P.P.) was available in 3 particle size ranges: 0-15 microns (Grade "A"), 50-100 microns (Grade "B"), and 50-300 microns (Grade "C").

Using an effective disintegrant concentration from part $D$ of this section (2\%), the three varlous grades of P.V.P.P. were combined by mixing in a stainless-steel twin shell blender with three different matrices of varying flow properties. The recording powder flowmeter was used to evaluate the effects of particle size of disintegrant on powder flow.

Using a Colton rotary tablet press at a speed of approximately 600 tablets/minute, the various grades of P.V.P.P. and exciplents were tableted according to the following formulation: 


\begin{tabular}{lc} 
Aspirin & $30.0 \%(w / w)$ \\
P.V.P.P. & $2.0 \%(w / w)$ \\
Talc , or C) & $0.5 \%(w / w)$ \\
Excipient & q.s. \\
\hline & $100.0 \%$
\end{tabular}

Tablet weight, hardness, riability, thickness and disintegration tests were carried out by previously described methods.

Dissolution of aspirin in the formulation was carrled out in a medium of $0.1 \mathrm{~N} \mathrm{HCl}$ at $37^{\circ} \mathrm{C}$. A scanning ultraviolet (U.V.) spectrophotometer was used to determine the $\lambda_{\max }$ of the given lot of aspirin, and all dissolution was carried out at this wavelength. The data represented in this section can be seen in Tables XXII-XXV and F1g. 9-11.

From examination of the above data, one particle slze (Grade C) was chosen. A concentration profile of P.V.P.P., grade C was obtained by incorporating concentrations of P.V.P.P. at 1, 2, 5, 10 and $20 \%$ (w/w) with a control, into the exclpient system by mixing for 15 minutes in a stainless-steel twin shell blender. Calcium phosphate (Emcompress) was chosen for its resistance to changes in flow. Using the recording powder flowneter described earlier, the powder systems were analyzed for mass flow and deviation from linear flow. This data appears in Table XXVI.

The disintegrant was then added in the same concentrations to a multivitamin formulation by mixing all ingredients for fifteen minutes in a stainless-steel twin shell blender. The formulation 
was as follows:

\begin{tabular}{lc} 
Riboflavin $\left(\mathrm{B}_{2}\right)$ & $0.7 \%(\mathrm{w} / \mathrm{w})$ \\
Pyridoxin ( $\left.{ }_{6}\right)$ & $1.0 \% \quad(\mathrm{w} / \mathrm{w})$ \\
Niacin & $7.0 \%$ \\
Ascorbic Acid (C) & $20.0 \%$ \\
Mag. Stearate & $0.5 \%$ \\
P.V.P.P. (grade C) & $\mathrm{X.X \%}$ \\
Emcompress & 9.8. \\
\hline
\end{tabular}

The formulation was then tableted on a Colton rotary tablet press at a speed of approximately 600 tablets/minute. The resulting tablets were evaluated for weight, thickness, hardness, friability and disintegration by the previously described procedures, and the data is represented graphically in Fig. 12-17.

Once a particle size of the disintegrant, compatibility of matrix/ excipient, and an effective concentration of disintegrant were found, a formulation considering all of variables was developed:

\begin{tabular}{lc} 
Pyridoxin $\left(\mathrm{B}_{6}\right)$ & $5.0 \%(\mathrm{w} / \mathrm{w})$ \\
P.V.P.P. (grade C) & $2.0 \%$ \\
Mag. Stearate & $0.5 \%$ \\
Emcompress & $\mathrm{q.3.}$ \\
\hline & $100 \%$
\end{tabular}

The ingredients were mixed for fifteen minutes in a stainless-steel twin shell blender and subsequently tableted using a colton rotary tablet press. Again, the approximate speed of the press was 
600 tablets/minute. The tablets were tested for weight, thickness, hardness, frlability, and disintegration, by the previously described methods. The data is listed in Table XXVII.

Dissolution was carried out in $0.1 \mathrm{~N} \mathrm{HCl}$ at $37^{\circ} \mathrm{C}$. A scanning ultraviolet (U.V.) spectrophotometer was used to determine the $\lambda_{\max }$ for the given lot of pyridoxine and three subsequent dissolutions were run at this wavelength. These dissolution curves can be seen in Fig. 19 . Content uniformity was performed by placing a tablet in a vial, and allowing it to fully dissolve in the medium over a period of 30 minutes. After suitable dilution, the absorbance of the solution was measured at the $\lambda_{\max }$ previously determined for pyridoxine. This procedure was repeated for thirty tablets. 
RESULTS AND DISCUSSION

Because it was a new experimental device, the compactor used for producing the intra and extra-granular disintegrant systems was calibrated. The various excipients were tested for density and particle size distribution by sieve analysis. The results are listed in Table III. The densities and particle size distributions of the excipients under the various experimental conditions are compiled in Tables IV-IX. These values became the standards for comparison of subsequent work.

\section{A. Compacted Dibasic Calcium Phosphate (Tables IV, V):}

For dibasic calcium phosphate, compaction at any machine setting led to particle sizes larger than the standard. As the auger screw speed increased, there was a tendency for the particle size to increase to a point, and then drop slightly. This effect was observed at both slow and fast roller speeds. However, this drop in particle size was not nearly so low as that for the lowest screw setting value. As the auger screw speed increased, the amount of powder forced between the rollers increased, and a larger particle was produced as the result of a thicker, denser band. However, when the highest screw speed was used, the resulting particle size decreased slightly, possibly because when large particles are milled, fracture takes place. This fracture can tend to lower the overall particle size because of breakage and 
CONTROL DATA: DENSITY \& SEIVE ANALYSIS OF EXCIPIENTS PRIOR

TO COMPACTION.

\begin{tabular}{|c|c|c|c|}
\hline \multirow{2}{*}{ Excipients: } & \multirow[t]{2}{*}{ Calcium Phosphate } & \multirow[t]{2}{*}{ Lactose } & \multirow{2}{*}{ 1:1 $\frac{\text { Calcium Phosphate }}{\text { Lactose }}$} \\
\hline & & & \\
\hline \multicolumn{4}{|l|}{ Density: } \\
\hline Bulk- & 0.704 & 0.633 & 0.759 \\
\hline Tapped- & 1.111 & 0.909 & 1.111 \\
\hline \multicolumn{4}{|l|}{ Seive Analysis: } \\
\hline$\%$ Left on \#30 Mesh & 0.0 & 0.0 & 0.0 \\
\hline$\%$ Left on $\# 50$ Mesh & 0.2 & 0.0 & Trace $(0.0)$ \\
\hline$\%$ Left on \#100 Mesh & 7.2 & 4.3 & 5.8 \\
\hline$\%$ Left on \#200 Mesh & 32.3 & 49.6 & 25.8 \\
\hline$\%$ Left on \#325 Mesh & 53.2 & 7.4 & 30.5 \\
\hline$\%$ Left on Base & 7.1 & 38.7 & 37.9 \\
\hline \multicolumn{4}{|l|}{ Geometric Mean } \\
\hline Diameter (in microns) & 77.5 & 71.6 & 64.0 \\
\hline
\end{tabular}

* Mixed in a stainless-steel twin shell blender for fifteen minutes 
CALCIUM PHOSPHATE SLOW ROLLER COMPACTOR PROFILE

\begin{tabular}{|c|c|c|c|c|c|c|c|c|c|c|c|c|}
\hline $\begin{array}{l}\text { Pressure }^{a}: \\
\text { Screw Speed }^{b} \text { : }\end{array}$ & 1 & $\begin{array}{c}0 \text { ATM } \\
3\end{array}$ & $\begin{array}{c}\text { Pressure } \\
6\end{array}$ & 9 & 30 & $\begin{array}{c}\text { ATM } \mathrm{Pr} \\
3\end{array}$ & $\begin{array}{c}\text { essure } \\
6\end{array}$ & 9 & 30 & $\begin{array}{c}\text { ATM } \\
3\end{array}$ & $\begin{array}{l}\text { sure } \\
6\end{array}$ & 9 \\
\hline \multicolumn{13}{|c|}{ Density $(\mathrm{gm} / \mathrm{ml})$ : } \\
\hline Bulk- & 0.926 & 0.962 & $\mathrm{U}$ & U & 0.909 & 0.980 & 0.961 & 0.980 & 0.962 & 1.000 & $\mathbf{U}$ & $\mathrm{U}$ \\
\hline Tapped- & 1.25 & 1.35 & U. & U & 1.35 & 1.39 & 1.39 & 1.02 & 1.39 & 1.39 & U & U \\
\hline \multicolumn{13}{|c|}{ Seive Analysis ${ }^{c}$ : } \\
\hline \#30 & 45.1 & 28.7 & U & U & 25.5 & 38.4 & 40.9 & 35.3 & 35.5 & 41.1 & $\mathrm{U}$ & U \\
\hline \#50 & 16.2 & 15.8 & $\mathrm{U}$ & $\mathrm{U}$ & 15.4 & 16.5 & 16.7 & 16.2 & 19.0 & 20.1 & $\mathrm{U}$ & U \\
\hline$\# 100$ & 7.0 & 8.2 & $\mathrm{U}$ & U & 6.8 & 6.9 & 8.0 & 8.7 & 8.9 & 8.9 & $\mathrm{U}$ & U \\
\hline$\# 200$ & 12.6 & 29.3 & $\mathrm{U}$ & U & 34.8 & 18.2 & 18.1 & 23.5 & 25.9 & 11.7 & U & U \\
\hline \#325 & 16.4 & 13.3 & $\mathrm{U}$ & $\mathrm{U}$ & 15.0 & 16.0 & 12.7 & 13.7 & 9.7 & 15.4 & $\mathrm{U}$ & U \\
\hline Base & 2.6 & 4.2 & U & U & 2.5 & 4.0 & 3.1 & 2.2 & 2.5 & 2.0 & $\mathrm{U}$ & U \\
\hline
\end{tabular}

Geometric Mean

$\begin{array}{lll}327.7 & 234.8 \quad U\end{array}$
a. Roller pressure in atmospheres (ATM)
b. Auger screw speed (see Methodology)
c. Percent retained on seive screen
d. In microns 
CALCIUM PHOSPHATE FAST ROLLER COMPACTOR PROFILE

\begin{tabular}{|c|c|c|c|c|c|c|c|c|c|c|c|c|}
\hline $\begin{array}{l}\text { Pressure }^{a}: \\
\text { Screw Speed }^{b} \text { : }\end{array}$ & 1 & $\begin{array}{c}30 \text { ATM F } \\
3\end{array}$ & $\begin{array}{c}\text { Pressure } \\
6\end{array}$ & 9 & 1 & $\begin{array}{c}\text { ATM F } \\
3\end{array}$ & $\begin{array}{c}\text { Pressure } \\
6\end{array}$ & 9 & 1 & $\begin{array}{c}0 \text { ATM I } \\
3\end{array}$ & $\begin{array}{c}\text { Pressure } \\
6\end{array}$ & 9 \\
\hline \multicolumn{13}{|c|}{ Density $(\mathrm{gm} / \mathrm{m} 1)$ : } \\
\hline $\mathrm{Bu} 1 \mathrm{k}-$ & 0.769 & 0.926 & 0.926 & 0.877 & 0.769 & 0.877 & 0.943 & $0: 909$ & 0.746 & 0.893 & $\mathbf{U}$ & $\mathrm{U}$ \\
\hline Tapped- & 1.16 & 1.39 & 1.39 & 1.35 & 1.32 & 1.37 & 1.39 & 1.35 & 1.19 & 1.35 & $\mathrm{U}$ & $\mathrm{U}$ \\
\hline \multicolumn{13}{|c|}{ Seive Analysis ${ }^{c}$ : } \\
\hline \#30 & 6.5 & 24.4 & 27.4 & 18.7 & 6.3 & 28.8 & 26.6 & 23.9 & 9.6 & 22.5 & $\mathrm{U}$ & $\mathrm{U}$ \\
\hline$\# 50$ & 7.6 & 17.5 & 17.9 & 16.5 & 4.2 & 17.8 & 16.7 & 15.7 & 7.7 & 16.3 & $\mathrm{U}$ & $\mathrm{U}$ \\
\hline$\# 100$ & 21.5 & 8.8 & 9.8 & 10.7 & 14.5 & 6.9 & 8.2 & 5.9 & 13.0 & 11.9 & $\mathrm{U}$ & $\mathrm{U}$ \\
\hline$\# 200$ & 52.1 & 35.2 & 33.7 & 42.9 & 57.0 & 32.2 & 33.5 & 46.8 & 57.8 & 35.0 & $\mathrm{U}$ & $\mathrm{U}$ \\
\hline$\# 325$ & 10.4 & 11.0 & 8.3 & 9.0 & 16.7 & 10.6 & 12.8 & 6.1 & 9.1 & 11.7 & $\mathrm{U}$ & $\mathrm{U}$ \\
\hline Base & 1.7 & 2.7 & 2.1 & 1.8 & 0.7 & 3.2 & 2.1 & 1.4 & 2.6 & 2.6 & $\mathbf{U}$ & $\mathrm{U}$ \\
\hline \multicolumn{13}{|l|}{ Geometric Mean } \\
\hline Diameter ${ }^{d}:$ & 151.3 & 227.6 & 252.1 & 206.5 & 133.1 & 246.7 & 233.0 & 225.0 & 152.1 & 218.5 & $\mathrm{U}$ & $\mathrm{U}$ \\
\hline
\end{tabular}
a. Roller pressure in atmospheres (ATM)
b. Auger screw speed (see Methodology)
c. Percent retained on seive screen
d. In microns 
production of "fines" or small bits and pieces of granule. This break-up may have occurred only at the highest screw speed setting when the extreme rate of speed exerted undue force on the powder between the rollers.

When set at screw speeds \#6 and \#9, the compactor was unable to compact at 70 atmosphers (ATM) pressure at either roller speed. This problem can easily be explained by the presence of too much powder under too great a pressure, at too great a speed.

The compactor would also not run at $30 \mathrm{ATM}$, slow roller, and screw speeds \#6 and \#9. This problem may have been caused by the fact that the dwell time for the powder is greatest on a slow roller, and at 30 ATM pressure, more powder may have been forced between the rollers. At the fast auger screw speeds, the flow of powder to the rollers may have been too fast; however, this condition was not seen at 50 ATM or at 30 ATM with the fast roller speed.

\section{B. Compacted Lactose 80M (Tables VI, VII):}

Similar to calcium phosphate, particle size increased when lactose was run through the compactor at any given machine setting. Particle size generally tended to increase up to the \#6 screw speed setting, and decrease slightly under the \#9 screw speed setting. This effect was also seen with the compacted calcium phosphate, and the mechanism was probably the same for both excipients.

The compactor was unable to run at many of the lower screw speeds for most pressures. This observation was the reverse of that seen for the calcium phosphate and could possibly be explained by the small 


\section{LACTOSE SLOW ROLLER COMPACTOR PROFILE}

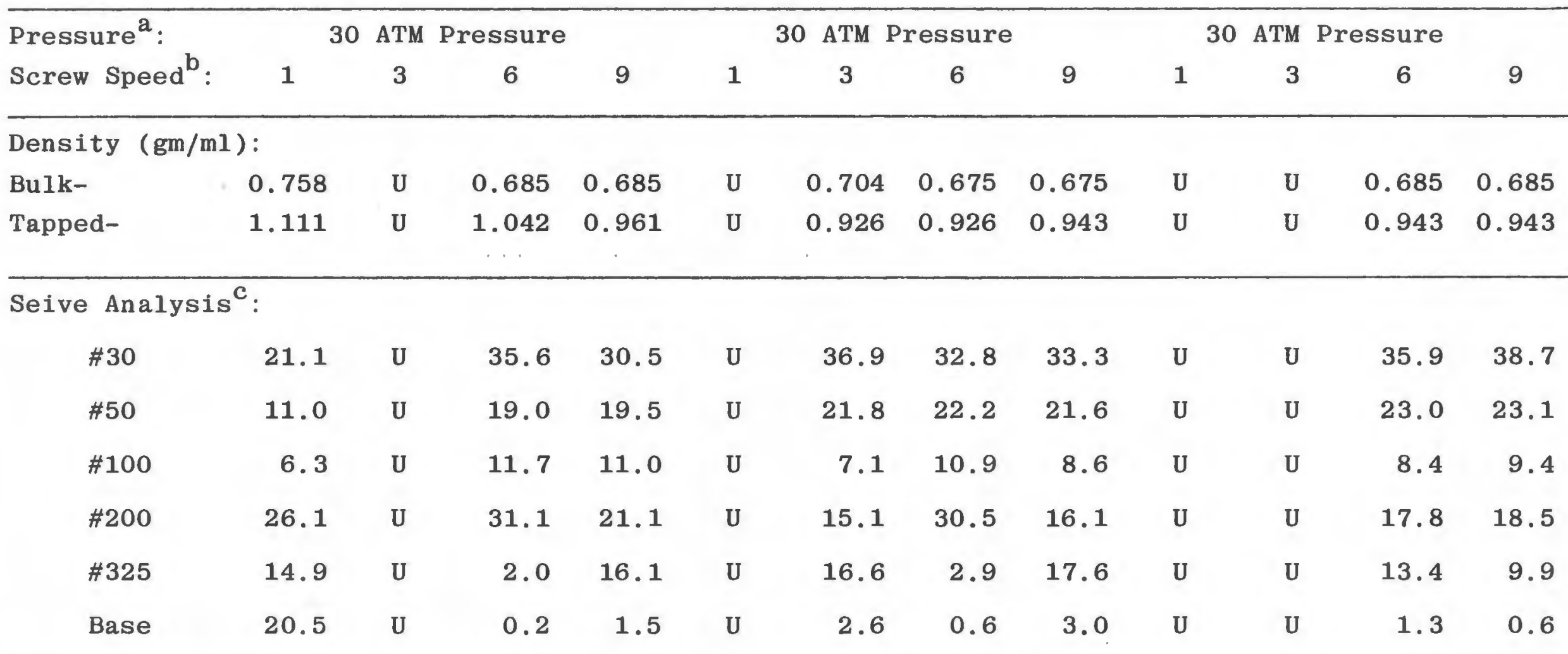

\section{Geometric Mean}

Diameter

326.1264 .4

$297.8 \quad 315.6 \quad 275.2 \quad U$

$\begin{array}{lll}\mathrm{U} & 310.7 & 340.7\end{array}$
a. Roller pressure in atmospheres (ATM)
b. Auger screw speed (see Methodology)
c. Percent retained on seive screen
d. In microns 
LACTOSE FAST ROLLER COMPACTOR PROFILE

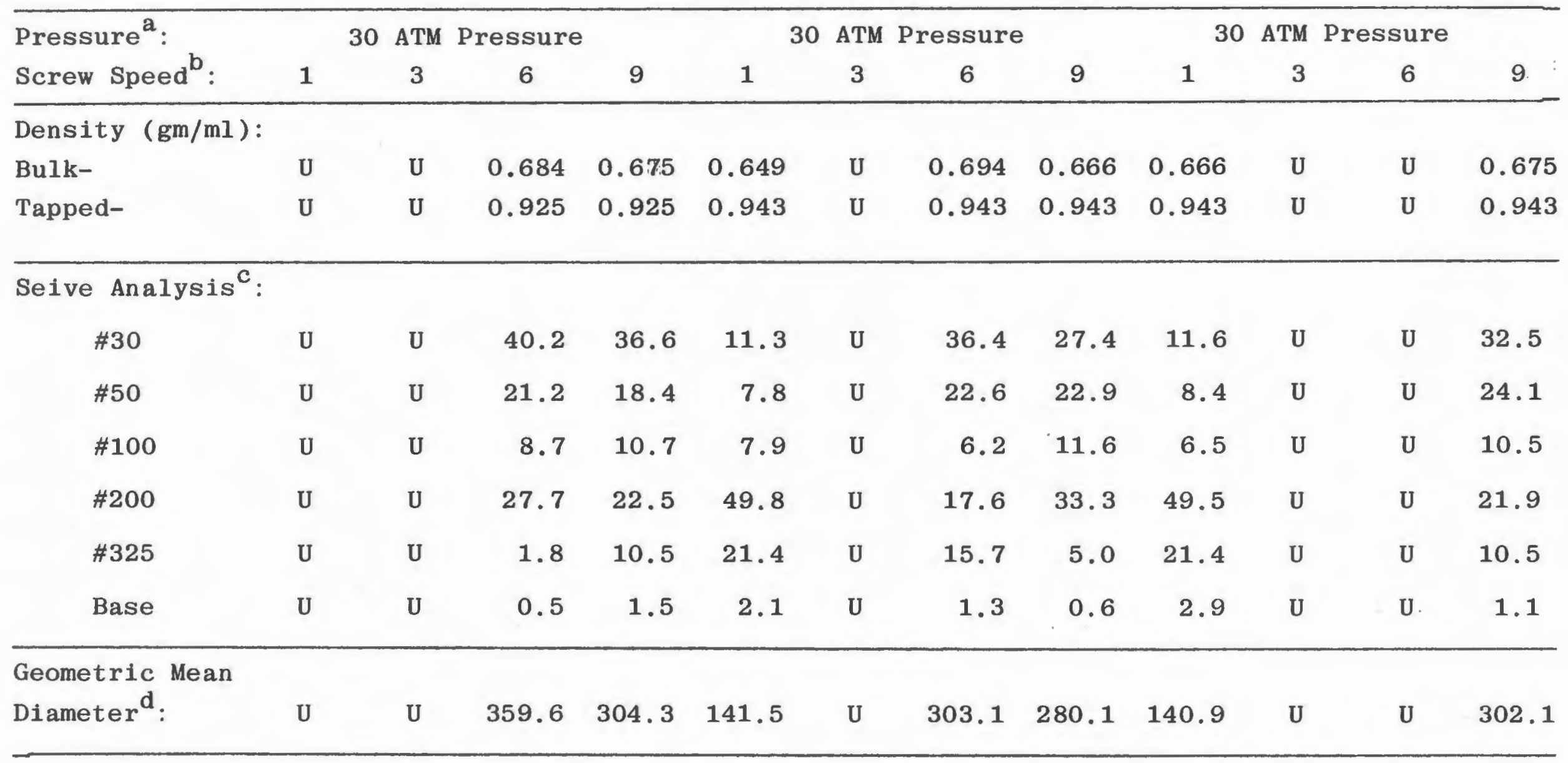
a. Roller pressure in atmospheres (ATM)
b. Auger screw speed (see Methodology)
c. Percent retained on seive screen
d. In microns 
density difference and the larger amount of fine particles in the lactose which might either require more powder to be compressed at one time or might not be as compressible as the calcium phosphate.

\section{Compacted Calcium Phosphate/Lactose, 1:1 (Tables VIII, IX):}

When calcium phosphate and lactose, in a 1:1 ratio were compacted together, any machine setting increased particle size. Since this effect was seen for each substance alone, this result was expected. Again, the particle size decreased slightly from the \#6 to \#9 screw speeds. However, the trend to increase particle size at the lower screw speed settings, although evident, was much more variable than when elther exciplent was run by itself. In fact, at 30 ATM pressure, there was 1ittle change in particle size when auger screw speed varied.

Since the compactor was able to run at all settings for the mixture of excipients, the complete set of data was subjected to a step-wise regression, with the following variables:

$$
\begin{aligned}
& \mathrm{X}_{1}=\text { Auger Screw Speed } \\
& \mathrm{X}_{2}=\text { Roller Pressure } \\
& \mathrm{X}_{3}=\text { Roller Speed } \\
& \mathrm{Y}=\text { Geometric Mean Diameter } \\
& \mathrm{X}^{\circ}=\text { Control Geometric Mean Diameter }
\end{aligned}
$$

The results showed that the most important factor in the increase in particle size was the roller speed. The next most significant factor was the auger screw speed, and the least significant factor was the roller pressure. The regression was performed using a statistical 
CALCIUM PHOSPHATE/LACTOSE (1:1) SLOW ROLLER COMPACTOR PROFILE

\begin{tabular}{|c|c|c|c|c|c|c|c|c|c|c|c|c|}
\hline \multirow{2}{*}{$\begin{array}{l}\text { Pressure }^{a}: \\
\text { Screw Speed }^{b} \text { : }\end{array}$} & \multicolumn{2}{|c|}{30 АTM F } & \multirow{2}{*}{$\begin{array}{c}\text { Pressure } \\
6\end{array}$} & \multirow[b]{2}{*}{9} & \multicolumn{4}{|c|}{30 ATM Pressure } & \multirow{2}{*}{3} & \multirow{2}{*}{$\begin{array}{c}30 \text { ATM } \\
3\end{array}$} & \multirow{2}{*}{$\begin{array}{c}\text { Pressure } \\
6\end{array}$} & \multirow[b]{2}{*}{9} \\
\hline & 1 & 3 & & & 1 & 3 & 6 & 9 & & & & \\
\hline \multicolumn{13}{|c|}{ Density $(\mathrm{gm} / \mathrm{ml})$ : } \\
\hline Bulk- & 0.925 & 0.925 & 0.925 & 0.862 & 0.806 & 0.925 & 0.925 & 0.862 & 0.833 & 0.862 & 0.877 & 0.892 \\
\hline Tapped- & 1.136 & 1.136 & 1.162 & 1.162 & 1.063 & 1.190 & 1.136 & 1.136 & 1.111 & 1.136 & 1.162 & 1.162 \\
\hline \multicolumn{13}{|c|}{ Seive Analysis ${ }^{c}$ : } \\
\hline \#30 & 34.5 & 35.7 & 31.1 & 34.6 & 36.8 & 30.4 & 36.7 & 38.4 & 40.7 & 34.2 & 40.6 & 44.0 \\
\hline \#50 & 18.2 & 17.8 & 20.6 & 19.3 & 18.5 & 23.1 & 20.6 & 23.1 & 15.7 & 22.4 & 22.5 & 19.1 \\
\hline$\# 100$ & 9.1 & 10.2 & 10.6 & 8.9 & 4.6 & 10.4 & 7.7 & 9.3 & 7.5 & 8.7 & 8.6 & 7.0 \\
\hline$\# 200$ & 25.1 & 16.2 & 24.5 & 14.3 & 20.5 & 17.1 & 12.6 & 13.7 & 15.4 & 14.8 & 12.7 & 11.4 \\
\hline
\end{tabular}

Geometric Mean

Diameter ${ }^{\mathrm{d}}$

$\begin{array}{llllllllllll}284.3 & 276.9 & 280.3 & 272.4 & 265.6 & 268.1 & 286.6 & 329.7 & 295.1 & 279.1 & 334.1 & 326.9\end{array}$
a. Roller pressure in atmospheres (ATM)
b. Auger screw speed (see Methodology)
c. Percent retained on seive screen
d. In microns 


\section{CALCIUM PHOSPHATE/LACTOSE ( $1: 1)$ FAST ROLLER COMPACTOR PROFILE}

\begin{tabular}{|c|c|c|c|c|c|c|c|c|c|c|c|c|}
\hline $\begin{array}{l}\text { Pressure }^{\mathrm{a}}: \\
\text { Screw Speed }^{\mathrm{b}} \text { : }\end{array}$ & 1 & $\begin{array}{c}30 \text { ATM F } \\
3\end{array}$ & $\begin{array}{c}\text { Pressure } \\
6\end{array}$ & 9 & 1 & $\begin{array}{c}30 \text { ATM P } \\
3\end{array}$ & $\begin{array}{c}\text { Pressure } \\
6\end{array}$ & 9 & 1 & $\begin{array}{c}30 \text { ATM } \\
3\end{array}$ & $\begin{array}{c}\text { Pressur } \\
6\end{array}$ & 9 \\
\hline \multicolumn{13}{|c|}{ Density $(\mathrm{gm} / \mathrm{ml})$ : } \\
\hline Bulk- & 0.833 & 0.847 & 0.833 & 0.862 & 0.781 & 0.833 & 0.862 & 0.833 & 0.769 & 0.833 & 0.833 & 0.833 \\
\hline Tapped- & 1.086 & 1.136 & 1.136 & 1.162 & 1.136 & 1.136 & 1.136 & 1.136 & 1.111 & 1.111 & 1.111 & 1.111 \\
\hline \#30 & 37.0 & 35.2 & 33.7 & 36.7 & 13.1 & 33.5 & 31.5 & 29.7 & 4.5 & 33.2 & 36.6 & 28.4 \\
\hline$\# 50$ & 19.2 & 20.7 & 16.8 & 18.5 & 5.8 & 17.8 & 18.1 & 15.8 & 3.3 & 18.7 & 16.7 & 15.9 \\
\hline$\# 100$ & 8.9 & 11.4 & 8.2 & 9.4 & 9.2 & 8.8 & 12.7 & 7.5 & 4.3 & 9.7 & 5.7 & 8.8 \\
\hline
\end{tabular}

\section{Geometric Mean}

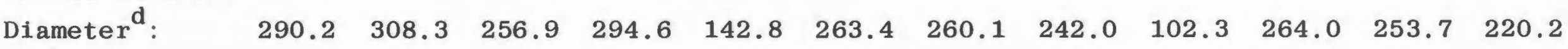
a. Roller pressure in atmospheres (ATM)
b. Auger screw speed (see Methodology)
c. Percent retained on seive screen
d. In microns 
program titled "SAS." The actual results of the regression are tabulated in Appendix III.

\section{Tablet Characteristics of Compacted Materials (Table X):}

After compaction the systems under study were lubricated and tableted either as a mixture of as a single entity on a Stokes Model F, single punch press which was computer-instrumented. The instrumentation consisted of pressure-sensitive transducers placed at the heads of the machine punches. The output from these transducers was relayed to a digital computer which monitored both applied and transmitted forces. In this way, it was easy to keep the applied force constant during tableting .

During the compressing operation, the weight adjustment setting on the tablet press was maintained at a constant level; thus the volume of powder fill remained constant. It should be noted therefore, that the variation in tablet weights, as seen in Table $\mathrm{X}$, reflects the change in density of the six powders.

It should be noted further that when the applied pressures for the tablet compression are similar (3600-4000 1bs.), the mean hardness values for the several excipients and mixtures were likewise similar (7-9 kg.). Hardness did not change significantly with the various excipient systems, although in the physical mixtures of compacted exciplents, hardness did appear to rise slightly with increasing calcium phosphate concentration. 
PHYSICAL PROPERTIES OF TABLETS MADE FROM COMPACTED FORMULATIONS

(CALCIUM PHOSPHATE, LACTOSE)

\begin{tabular}{|c|c|c|c|c|c|c|}
\hline Formulation & 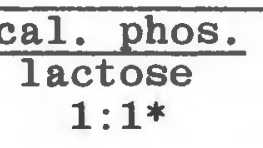 & $\begin{array}{l}\text { calcium } \\
\text { phosphate }\end{array}$ & lactose & $\begin{array}{c}\frac{\text { cal. phos. }}{\text { lactose }} \\
25: 75\end{array}$ & $\begin{array}{c}\frac{\text { cal. phos. }}{\text { lactose }} \\
50: 50\end{array}$ & 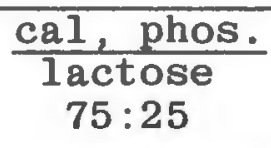 \\
\hline \multicolumn{7}{|l|}{ Applied } \\
\hline Pressure (lbs.) & 4031 & 3613 & 3964 & 3694 & 3907 & 3890 \\
\hline R.S.D. & 10.6 & 15.2 & 6.8 & 9.6 & 8.1 & 8.5 \\
\hline Mean Weight (mg.) & 275 & 285 & 236 & 258 & 269 & 278 \\
\hline R.S.D. & 0.9 & 3.6 & 1.4 & 1.4 & 2.2 & 1.9 \\
\hline $\begin{array}{c}\text { Mean Thickness } \\
(\mathrm{mm} .)\end{array}$ & \multicolumn{2}{|c|}{ Mean Thickness } & 3.45 & 3.54 & 3.39 & 3.25 \\
\hline R.S.D. & 0.5 & 1.9 & 0.7 & 0.6 & 1.7 & 0.7 \\
\hline Mean Hardness ( $\mathrm{kg}$. ) & 8.2 & 8.9 & 8.7 & 6.7 & 7.9 & 8.6 \\
\hline Range. & $7.5-9.0$ & $4.3-11.3$ & $6.0-11.3$ & $5.3-8.8$ & $5.8-10.3$ & $6.5-11.3$ \\
\hline \multicolumn{7}{|l|}{ Mean Disintegration } \\
\hline Time (min.) & 33.0 & 120 & 1.3 & 4.6 & 27.5 & 93.0 \\
\hline Range & $30.8-35.8$ & 120 & $1.0-1.6$ & $3.1-6.3$ & $23.3-33.8$ & $70-120$ \\
\hline
\end{tabular}

* The 1:1 mixture was mixed before compaction while the last three $(25: 75,50: 50,75: 25)$ were physically mixed after compaction of the individual excipients. 
46

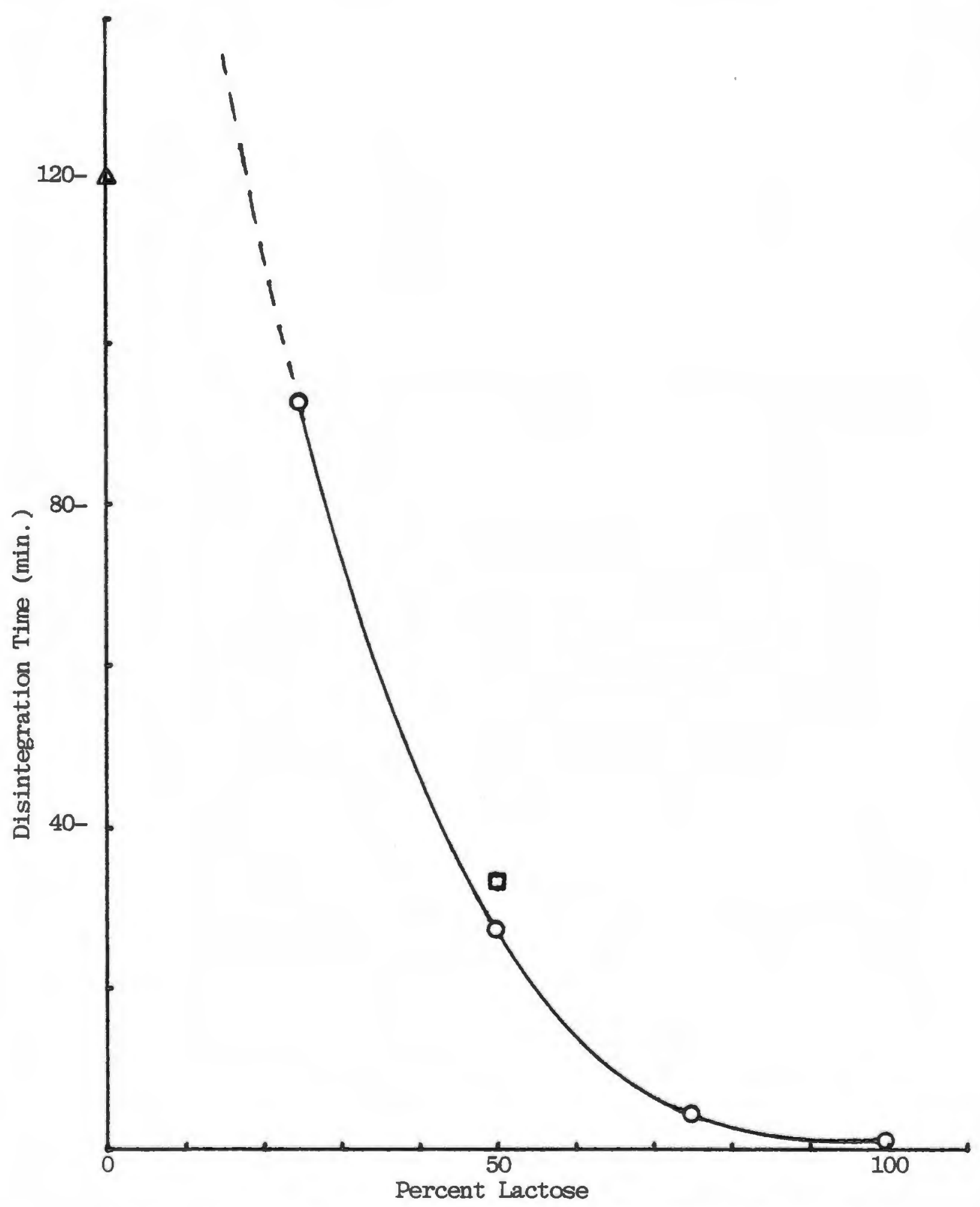

Fig. Change in Disintegration Time as Percent Lactose in Calcium Phosphate Dihydrate Increases in the Compacted System. ( 0 -Measured time, ingredients compacted separately, 0-Measured time, ingredients compacted together, $\Delta$-Value is in excess of plot, testing was discontinued) 
Under these pressure conditions, the calctum phosphate tablets falled to disintegrate within two hours, while the lactose tablets disintegrated within two minutes, However, the lactose systems may have undergone more of a solvation phenomenon in the aqueous disintegration medium, rather than ordinary disintegration. For the 1:1 mixture, the disintegration time was approximately one-half hour and the properties lent by the water-soluble component, lactose, were evident in the results for the mixture. It was also observed that as the lactose concentration increased, the disintegration time decreased. This relationship is illustrated in Fig. 8 .

By mixing calclum phosphate and lactose before compactions, disintegration time was not greatly altered from that of the physical mixtures after compaction (see columns 1 and 5 of Table X).

The effect of a disintegrant, corn starch, on the disintegration of one of these systems then became of interest. In order to find a system that would yleld a noticeable change in disintegration time, a system with a long disintegration time was sought. The calcium phosphate/lactose (75:25) system was chosen.

E. Starch in a Mixture of Compacted Excipients (Table XI):

Tableting of the systems where calctum phosphate and lactose were compacted separately and the starch was added later, was 
carried out under constant applied pressure, as before. The hardness values for this series of tablets fell within a range of 7.5-10 kilograms. As expected, the disintegration time decreased as starch concentration increased.

The effects of corn starch first became evident at a low concentration of one-half percent $(w / w)$; and at this level, disintegration time was reduced by $50 \%$. If a maximum target disintegration time can be set at 30 minutes or less, one percent starch would seem to be effective. A two percent concentration yielded a disintegration time of two to five minutes.

These were surprisingly effective lower concentrations of corn starch than have been reported by conventional literature sources (65-67). Although these sources have stated that concentrations of five to twenty percent $(w / w)$ were effective, concentrations above five percent in this system have yielded extremely fast disintegration rate. These may have been too fast to be considered optimum for this system and may comprise an "overk1l1" approach to tablet disintegration.

It should also be noted that there did not seem to be a significant change in hardness as the starch concentration increased. 
PHYSICAL PROPERTIES OF TABLETS MADE FROM FORMULATIONS* WITH INCREASING AMOUNTS OF STARCH ADDED

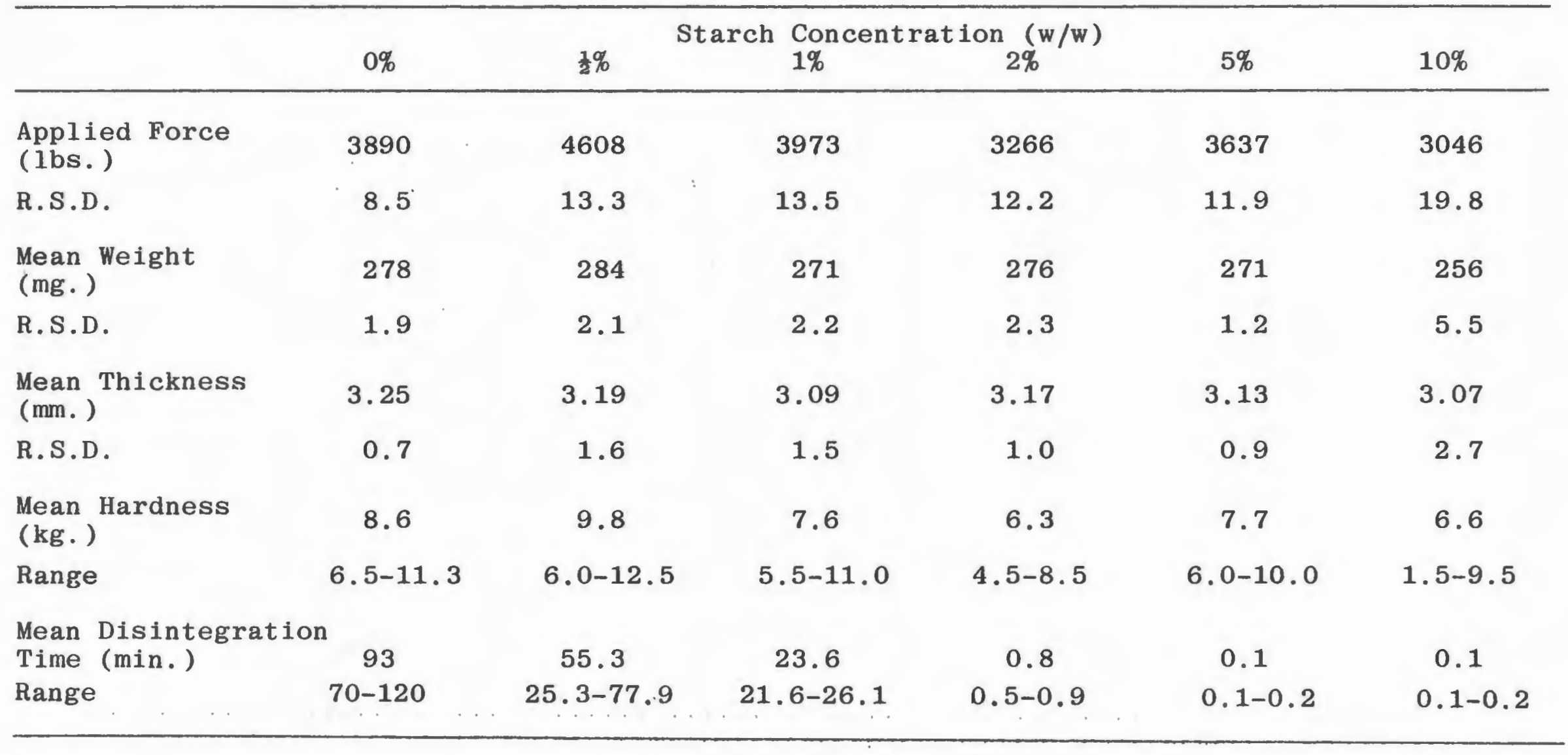

* Calcium phosphate/lactose, 75:25, compacted separately, then starch added 
F. Starch in Compacted Mixture of Excipients (Table XII):

In the second system, where the calcium phosphate and the lactose were compacted together with the starch being added later, it was obvious that adequate disintegration did not obtain at a concentration of two percent, but was reached at five percent of starch in the formulation.

The control system, when compared to the first control system (separately compacted excipients) gave a disintegration time in excess of two hours. No decrease in disintegration time was observed for starch added in concentrations of one-half, one and two percent. A disintegrant level of five percent resulted in a disintegration time range of one to four minutes. A value between two and five percent may have produced intermediate values.

This phenomenon may have resulted from the fact that lactose is the water soluble excipient in this system, and may have been "hidden" within the calcium phosphate, resulting in an exciplent with properties closely related to the calcium phosphate (high disintegration times). Again, there were only slight changes in hardness as starch concentration increased.

G. Starch Compacted in with the Mixture of Excipients (Table XIII):

In the third test system, where the two excipients and the starch were compacted together, disintegration under 30 minutes was again achieved by using only one percent starch in the formulation. An average disintegration time of three minutes was also achieved with two percent starch in the formulation. 
PHYSICAL PROPERTIES OF TABLETS MADE FROM FORMULATIONS* WITH INCREASING AMOUNTS OF STARCH ADDED

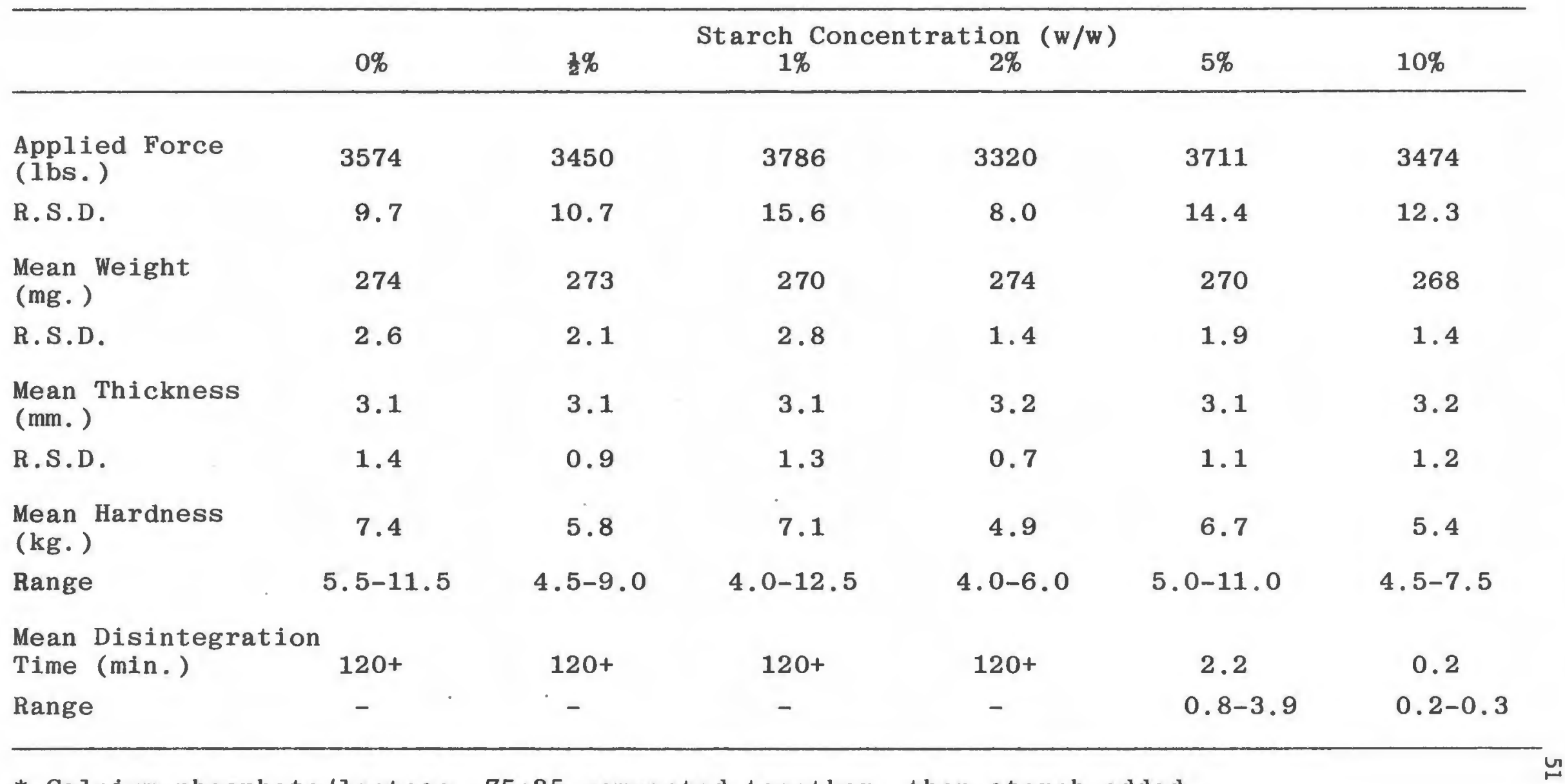

* Calcium phosphate/lactose, 75:25 compacted together, then starch added 
PHYSICAL PROPERTIES OF TABLETS MADE FROM FORMULATIONS* With INCREASING AMOUNTS OF STARCH ADDED

\begin{tabular}{|c|c|c|c|c|c|c|}
\hline & $0 \%$ & $\frac{1}{2} \%$ & $\begin{array}{c}\text { reh Concent } \\
1 \%\end{array}$ & $\operatorname{ion}_{2 \%}(w / w)$ & $5 \%$ & $10 \%$ \\
\hline $\begin{array}{l}\text { Applied Force } \\
\text { (1bs.) }\end{array}$ & 3574 & 3722 & 3835 & 3345 . & 3906 & 3676 \\
\hline R.S.D. & 9.7 & 7.8 & 8.8 & 9.6 & 13.9 & 12.1 \\
\hline $\begin{array}{l}\text { Mean Weight } \\
(\mathrm{mg} .)\end{array}$ & 274 & 272 & 276 & 274 & 270 & 274 \\
\hline R.S.D. & 2.6 & 3.0 & 1.6 & 1.9 & 1.9 & 1.7 \\
\hline $\begin{array}{l}\text { Mean Thickness } \\
(\mathrm{mm} .)\end{array}$ & 3.11 & 3.12 & 3.14 & 3.18 & 3.18 & 3.19 \\
\hline R.S.D. & 1.4 & 1.6 & 1.0 & 1.1 & 1.4 & 1.0 \\
\hline $\begin{array}{l}\text { Mean Hardness } \\
(\mathrm{kg} .)\end{array}$ & 7.4 & 6.1 & 6.3 & 5.5 & 7.9 & 7.7 \\
\hline Range & $5.5-11.5$ & $3.5-9.0$ & $5.0-8.0$ & $4.0-6.5$ & $5.5-11.0$ & $5.5-11.0$ \\
\hline $\begin{array}{l}\text { Mean Disintegra } \\
\text { Time (min.) }\end{array}$ & $120+$ & $120+$ & 20.5 & 2.7 & 0.3 & 0.2 \\
\hline Range & - & - & $13.2-27.8$ & $2.1-3.6$ & $0.3-0.4$ & $0.2-0.3$ \\
\hline
\end{tabular}

* Calcium phosphate/lactose 75:25, with starch being added prior to compaction of the system 
A one-half percent concentration of starch, however, was not effective in reducing the disintegration time to under two hours. Concentrations of one and two percent yielded adequate disintegration times; and these times differed from those of the previous system. This result may have been due to some intra-, and extragranular disintegrant alding both the disintegration and aggregation phenomena. However, by adding an intragranular disintegrant, there was no appreclable advantage over mixing of each ingredient separately. In fact, the disintegration process was more efficient when the tablet formulation was prepared by the latter method.

The sum effect of processing procedures on the disintegration process for the described pre-compression systems is illustrated in Fig. 9.

Also, as noted previously, there was no significant change in hardness as the starch concentration increased.

H. Evaluation of Low Levels of Tablet Disintegrants (Tables XIV-XXI): The data revealed that, while low level of tablet disintegrants have little effect on such parameters as tablet weight variation, thickness, and hardness, disintegration times were reduced significantly. In fact, even at concentrations as low as $0.25 \%(w / w)$, one disintegrant reduced disintegration time from greater than two hours, to just over one minutes; a hundred-fold increase in the rate of disintegration. At a concentration of one percent, seven of the disintegrants induced greater than a ten-fold decrease in disintegration time. One-half of the disintegrants reduced the disintegration 


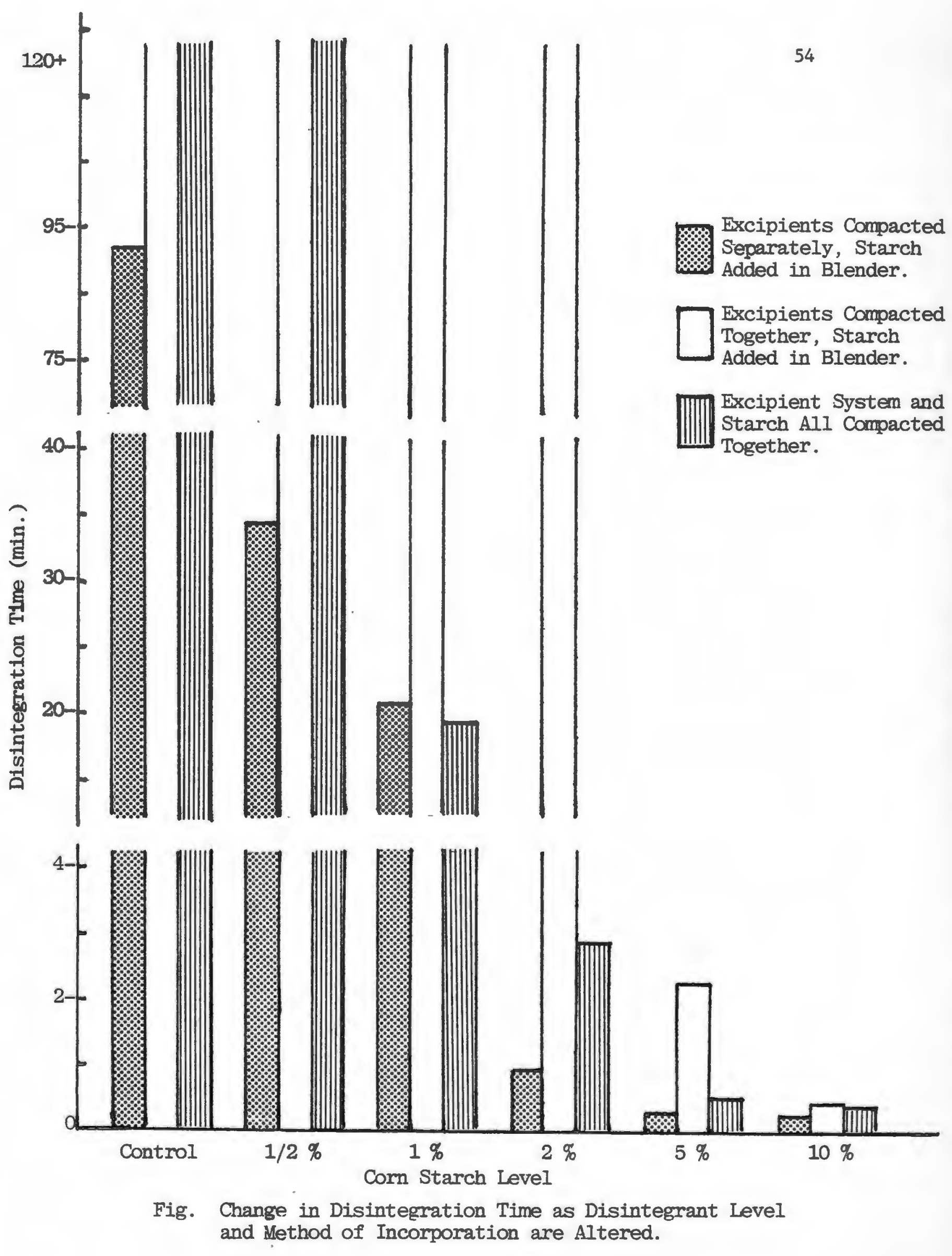


AMBERLITE IRP-88 CONCENTRATION PROFILE

Granulation and Tablet Properties

\begin{tabular}{|c|c|c|c|c|c|}
\hline Parameter & Control & \multicolumn{3}{|c|}{ Disintegrant Concentration } & $2 \%$ \\
\hline \multicolumn{6}{|l|}{ Flow: } \\
\hline Linearity ${ }^{*}$ & 19.5 & 19.6 & 19.4 & 19.3 & 18.9 \\
\hline $\begin{array}{l}\text { Flow Rate } \\
(\mathrm{gm} / \mathrm{sec})\end{array}$ & 241 & 234 & 223 & 211 & 201 \\
\hline \multicolumn{6}{|l|}{ Tablet: } \\
\hline $\begin{array}{l}\text { Weight } \\
\text { (mg) }\end{array}$ & 402 & 405 & 405 & 403 & 407 \\
\hline R.S.D. & 0.7 & 0.4 & 0.4 & 0.3 & 0.2 \\
\hline $\begin{array}{l}\text { Thickness } \\
(\mathrm{mm})\end{array}$ & 3.30 & 3.34 & 3.33 & 3.34 & 3.37 \\
\hline R.S.D. & 0.8 & 0.4 & 0.4 & 0.4 & 0.4 \\
\hline $\begin{array}{l}\text { Hardness } \\
(\mathrm{kg})\end{array}$ & 8.8 & 8.7 & 8.8 & 8.6 & 8.9 \\
\hline R.S.D. & 12.7 & 9.5 & 11.7 & 10.5 & 11.5 \\
\hline \multicolumn{5}{|c|}{ Disintegration } & 0.4 \\
\hline Range & - & $16.2-29.3$ & $5.3-11.2$ & $2.8-3.5$ & $0.3-0.5$ \\
\hline \multicolumn{6}{|c|}{ Applied } \\
\hline R.S.D. & 1.9 & 1.7 & 2.1 & 1.7 & 1.7 \\
\hline
\end{tabular}

* $\left(r^{2}-0.8\right) \times 100$, see Experimental section 
CLD CONCENTRATION PROFILE

Granulation and Tablet Properties

\begin{tabular}{|c|c|c|c|c|c|}
\hline Parameter & Control & \multicolumn{3}{|c|}{ Disintegrant Concentration } & $2 \%$ \\
\hline \multicolumn{6}{|l|}{ Flow: } \\
\hline Linearity* & 19.5 & 19.6 & 18.9 & 19.2 & 19.0 \\
\hline $\begin{array}{l}\text { Flow Rate } \\
(\mathrm{gm} / \mathrm{sec})\end{array}$ & 241 & 234 & 226 & 212 & 204 \\
\hline \multicolumn{6}{|l|}{ Tablet: } \\
\hline $\begin{array}{l}\text { Weight } \\
\text { (mg) }\end{array}$ & 402 & 406 & 407 & 403 & 397 \\
\hline R.S.D. & 0.7 & 0.5 & 0.4 & 0.4 & 1.0 \\
\hline $\begin{array}{l}\text { Thickness } \\
(\mathrm{mm})\end{array}$ & 3.30 & 3.35 & 3.33 & 3.32 & 3.30 \\
\hline R.S.D. & 0.8 & 0.4 & 0.6 & 0.5 & 0.8 \\
\hline $\begin{array}{l}\text { Hardness } \\
(\mathbf{k g})\end{array}$ & 8.8 & 8.8 & 9.0 & 8.9 & 8.9 \\
\hline R.S.D. & 12.7 & 12.3 & 10.1 & 12.8 & 11.3 \\
\hline $\begin{array}{l}\text { Disintegration } \\
\text { Time (min) }\end{array}$ & $120+$ & 1.2 & 0.8 & 0.3 & 0.3 \\
\hline Range & - & $0.5-1.9$ & $0.6-0.9$ & $0.3-0.4$ & $0.28-0.33$ \\
\hline $\begin{array}{l}\text { Applied } \\
\text { Pressure (Ibs) }\end{array}$ & 3600 & 3544 & 3841 & 3740 & 3491 \\
\hline R.S.D. & 1.9 & 2.0 & 1.7 & 1.7 & 3.7 \\
\hline
\end{tabular}

* $\left(r^{2}-0.8\right) \times 100$, see Experimental section 
AC-DI-SOL CONCENTRATION PROFILE

Granulation and Tablet Properties

\begin{tabular}{|c|c|c|c|c|c|}
\hline Parameter & Control & $\begin{array}{l}\text { Disintegrant } \\
\quad 0.25 \%\end{array}$ & $\begin{array}{l}\text { Concent } \\
0.5 \%\end{array}$ & $\begin{array}{r}\text { ation } \\
1 \%\end{array}$ & $2 \%$ \\
\hline \multicolumn{6}{|l|}{ Flow: } \\
\hline Linearity* & 19.5 & 19.5 & 19.6 & 19.2 & 19.2 \\
\hline $\begin{array}{l}\text { Flow Rate } \\
\text { (gm/sec) }\end{array}$ & 241 & 234 & 223 & 219 & 211 \\
\hline \multicolumn{6}{|l|}{ Tablet: } \\
\hline $\begin{array}{l}\text { Weight } \\
(\mathrm{mg})\end{array}$ & 402 & 402 & 405 & 402 & 401 \\
\hline R.S.D. & 0.7 & 0.3 & 0.3 & 0.2 & 0.3 \\
\hline $\begin{array}{l}\text { Thickness } \\
(\mathrm{mm})\end{array}$ & 3.30 & 3.27 & 3.29 & 3.28 & 3.31 \\
\hline R.S.D. & 0.8 & 0.6 & 0.5 & 0.5 & 0.4 \\
\hline $\begin{array}{l}\text { Hardness } \\
(\mathrm{kg})\end{array}$ & 8.8 & 9.9 & 9.7 & 9.1 & 8.4 \\
\hline R.S.D. & 12.7 & 10.2 & 9.2 & 12.1 & 12.2 \\
\hline $\begin{array}{l}\text { Disintegration } \\
\text { Time (min) }\end{array}$ & $120+$ & 4.8 & 1.9 & 0.6 & 0.5 \\
\hline Range & - & $3.1-5.5$ & $0.9-2.1$ & $0.5-0.7$ & $0.4-0.5$ \\
\hline $\begin{array}{l}\text { Applied } \\
\text { Pressure (lbs) }\end{array}$ & 3600 & 3767 & 3783 & 3852 & 3662 \\
\hline R.S.D. & 1.9 & 1.9 & 2.4 & 1.5 & 1.8 \\
\hline
\end{tabular}

* $\left(r^{2}-0.8\right) \times 100$, see Experimental section 
EXPLOTAB CONCENTRATION PROFILE

Granulation and Tablet Properties

\begin{tabular}{|c|c|c|c|c|c|}
\hline Parameter & Control & $\begin{array}{c}\text { Disintegran } \\
0.25 \%\end{array}$ & $\begin{array}{l}\text { nt Concen } \\
0.5 \%\end{array}$ & $\begin{array}{c}\text { ration } \\
1 \%\end{array}$ & $2 \%$ \\
\hline \multicolumn{6}{|l|}{ Flow: } \\
\hline Linearity ${ }^{*}$ & 19.5 & 19.4 & 19.6 & 19.4 & 19.5 \\
\hline $\begin{array}{l}\text { Flow Rate } \\
(\mathrm{gm} / \mathrm{sec})\end{array}$ & 241 & 233 & 228 & 222 & 217 \\
\hline \multicolumn{6}{|l|}{ Tablet: } \\
\hline $\begin{array}{l}\text { Weight } \\
\text { (mg) }\end{array}$ & 402 & 399 & 401 & 398 & 400 \\
\hline R.S.D. & 0.7 & 0.3 & 0.4 & 0.5 & 0.3 \\
\hline $\begin{array}{l}\text { Thickness } \\
\text { (mm) }\end{array}$ & 3.30 & 3.26 & 3.29 & 3.27 & 3.32 \\
\hline R.S.D. & 0.8 & 0.5 & 0.7 & 0.6 & 0.5 \\
\hline $\begin{array}{l}\text { Hardness } \\
(\mathrm{kg})\end{array}$ & 8.8 & 9.6 & 9.1 & 10.1 & 8.2 \\
\hline R.S.D. & 12.7 & 14.1 & 14.4 & 9.6 & 10.4 \\
\hline \multicolumn{6}{|l|}{ Disintegration } \\
\hline Range & - & $9.8-11.2$ & $3.2-6.1$ & $2.1-3.0$ & $0.9-1.3$ \\
\hline $\begin{array}{l}\text { Applied } \\
\text { Pressure (1bs) }\end{array}$ & 3600 & 3821 & 3693 & 3768 & 3595 \\
\hline R.S.D. & 1.9 & 1.4 & 1.4 & 1.6 & 1.7 \\
\hline
\end{tabular}

* $\left(r^{2}-0.8\right) \times 100$, see Experimental section 
POLYPLASDONE XL CONCENTRATION PROFILE

Granulation and Tablet Properties

\begin{tabular}{|c|c|c|c|c|c|}
\hline Parameter & Control & $\begin{array}{c}\text { Disintegrant } \\
0.25 \%\end{array}$ & $\begin{array}{l}\text { Concent } \\
0.5 \%\end{array}$ & $\begin{array}{r}\text { ration } \\
1 \%\end{array}$ & $2 \%$ \\
\hline \multicolumn{6}{|l|}{ Flow: } \\
\hline Linearity ${ }^{*}$ & 19.5 & 19.4 & 19.4 & 19.6 & 19.5 \\
\hline $\begin{array}{l}\text { Flow Rate } \\
\text { (gm/sec) }\end{array}$ & 241 & 244 & 240 & 232 & 219 \\
\hline Tablet: & . & & & & \\
\hline $\begin{array}{l}\text { Weight } \\
(\mathrm{mg})\end{array}$ & 402 & 406 & 403 & 396 & 388 \\
\hline R.S.D. & 0.7 & 0.3 & 0.5 & 1.5 & 1.0 \\
\hline $\begin{array}{l}\text { Thickness } \\
(\mathrm{mm})\end{array}$ & 3.30 & 3.34 & 3.30 & 3.29 & 3.24 \\
\hline R.S.D. & 0.8 & 0.4 & 0.6 & 0.6 & 0.6 \\
\hline $\begin{array}{l}\text { Hardness } \\
(\mathrm{kg})\end{array}$ & 8.8 & 8.8 & 9.0 & 7.7 & 8.4 \\
\hline R.S.D. & 12.7 & 12.0 & 15.2 & 17.6 & 5.7 \\
\hline $\begin{array}{l}\text { Disintegration } \\
\text { Time (min) }\end{array}$ & $120+$ & 17.8 & 6.5 & 2.7 & 0.4 \\
\hline Range & - & $17.2-18.4$ & $5.2-7.8$ & $1.4-3.9$ & $0.38-0.42$ \\
\hline $\begin{array}{l}\text { Applied } \\
\text { Pressure (lbs) }\end{array}$ & 3600 & 3676 & 3729 & 3594 & 3543 \\
\hline R.S.D. & 1.9 & 2.3 & 5.7 & 5.2 & 5.0 \\
\hline
\end{tabular}

* $\left(r^{2}-0.8\right) \times 100$, see Experimental section 
CORN STARCH U.S.P. CONCENTRATION PROFILE

Granulation and Tablet Properties

\begin{tabular}{|c|c|c|c|c|c|}
\hline \multirow[b]{2}{*}{ Parameter } & \multirow[b]{2}{*}{ Control } & \multicolumn{3}{|c|}{ Disintegrant Concentration } & \multirow[b]{2}{*}{$2 \%$} \\
\hline & & $0.25 \%$ & $0.5 \%$ & $1 \%$ & \\
\hline \multicolumn{6}{|l|}{ Flow: } \\
\hline Linearity* & 19.5 & 19.3 & 19.4 & 19.2 & 19.1 \\
\hline $\begin{array}{l}\text { Flow Rate } \\
(\mathrm{gm} / \mathrm{sec})\end{array}$ & 241 & 238 & 227 & 212 & 206 \\
\hline \multicolumn{6}{|l|}{ Tablet: } \\
\hline $\begin{array}{l}\text { Weight } \\
(\mathrm{mg})\end{array}$ & 402 & 403 & 403 & 404 & 404 \\
\hline R.S.D. & 0.7 & 0.3 & 0.4 & 0.4 & 0.6 \\
\hline $\begin{array}{l}\text { Thickness } \\
(\mathrm{mm})\end{array}$ & 3.30 & 3.31 & 3.31 & 3.30 & 3.33 \\
\hline R.S.D. & 0.8 & 0.4 & 0.4 & 0.5 & 0.7 \\
\hline $\begin{array}{l}\text { Hardness } \\
(\mathrm{kg})\end{array}$ & 8.8 & 8.5 & 8.4 & 9.1 & 8.6 \\
\hline R.S.D. & 12.7 & 7.3 & 9.8 & 11.2 & 10.5 \\
\hline $\begin{array}{l}\text { Disintegration } \\
\text { Time (min) }\end{array}$ & $120+$ & 55.8 & 54.2 & 16.5 & 12.0 \\
\hline Range & - & $28.6-63.2$ & $38.0-70.4$ & $12.2-20.8$ & $10.2-13.8$ \\
\hline $\begin{array}{l}\text { Applied } \\
\text { Pressure (lbs) }\end{array}$ & 3600 & 3557 & 3735 & 3826 & 3590 \\
\hline R.S.D. & 1.9 & 1.6 & 2.3 & 1.7 & 2.2 \\
\hline
\end{tabular}

* $\left(r^{2}-0.8\right) \times 100$, see Experimental section 
STA-RX 1500 STARCH CONCENTRATION PROFILE

Granulation and Tablet Properties

\begin{tabular}{|c|c|c|c|c|c|}
\hline Parameter & Control & $\begin{array}{c}\text { Disintegran } \\
0.25 \%\end{array}$ & $\begin{array}{l}\text { Concent } \\
0.5 \%\end{array}$ & $\begin{array}{r}\text { ration } \\
1 \%\end{array}$ & $2 \%$ \\
\hline \multicolumn{6}{|l|}{ Flow: } \\
\hline Linearity* & 19.5 & 19.4 & 19.6 & 19.2 & 19.1 \\
\hline $\begin{array}{l}\text { Flow Rate } \\
(\mathrm{gm} / \mathrm{sec})\end{array}$ & 241 & 231 & 220 & 212 & 201 \\
\hline \multicolumn{6}{|l|}{ Tablet: } \\
\hline $\begin{array}{l}\text { Weight } \\
(\mathrm{mg})\end{array}$ & 402 & 410 & 411 & 405 & 411 \\
\hline R.S.D. & 0.7 & 0.4 & 0.4 & 0.5 & 0.5 \\
\hline $\begin{array}{l}\text { Thickness } \\
(\mathrm{mm})\end{array}$ & 3.30 & 3.36 & 3.36 & 3.28 & 3.39 \\
\hline R.S.D. & 0.8 & 0.7 & 0.6 & 0.6 & 0.6 \\
\hline $\begin{array}{l}\text { Hardness } \\
(\mathrm{kg})\end{array}$ & 8.8 & 8.3 & 8.8 & 10.5 & 7.9 \\
\hline R.S.D. & 12.7 & 9.9 & 11.4 & 8.6 & 11.7 \\
\hline $\begin{array}{l}\text { Disintegration } \\
\text { Time (min) }\end{array}$ & $120+$ & 34.5 & 21.3 & 10.3 & 5.8 \\
\hline Range & - & $31.6-53.5$ & $18.6-34.0$ & $8.8-11.8$ & $3.8-7.8$ \\
\hline $\begin{array}{l}\text { Applied } \\
\text { Pressure (1bs) }\end{array}$ & 3600 & 3636 & 3745 & 4092 & 3512 \\
\hline R.S.D. & 1.9 & 1.6 & 1.6 & 5.6 & 2.5 \\
\hline
\end{tabular}

* $\left(r^{2}-0.8\right) \times 100$, see Experimental section 
GUAR GUM CONCENTRATION PROFILE

Granulation and Tablet Properties

\begin{tabular}{|c|c|c|c|c|c|}
\hline Parameter & Control & $\begin{array}{l}\text { Disintegrant } \\
0.25 \%\end{array}$ & $\begin{array}{l}\text { Concentr } \\
0.5 \%\end{array}$ & $\begin{array}{r}\text { ation } \\
1 \%\end{array}$ & $2 \%$ \\
\hline Flow: & & & & . & \\
\hline Linearity ${ }^{*}$ & 19.5 & 19.2 & 19.4 & 18.9 & -18.9 \\
\hline $\begin{array}{l}\text { Flow Rate } \\
\text { (gm/sec) }\end{array}$ & 241 & 238 & 233 & 218 & 196 \\
\hline \multicolumn{6}{|l|}{ Tablet: } \\
\hline $\begin{array}{l}\text { Weight } \\
(\mathrm{mg})\end{array}$ & 402 & 405 & 404 & 409 & 409 \\
\hline R.S.D. & 0.7 & 0.5 & 0.7 & 0.6 & 0.4 \\
\hline $\begin{array}{l}\text { Thickness } \\
(\mathrm{mm})\end{array}$ & 3.30 & 3.33 & 3.33 & 3.35 & 3.36 \\
\hline R.S.D. & 0.8 & 0.7 & 0.7 & 0.7 & 0.5 \\
\hline $\begin{array}{l}\text { Hardness } \\
(\mathrm{kg})\end{array}$ & 8.8 & 8.2 & 8.1 & 8.6 & 8.7 \\
\hline R.S.D. & 12.7 & 15.6 & 12.9 & 13.4 & 10.9 \\
\hline $\begin{array}{l}\text { Disintegration } \\
\text { Time (min) }\end{array}$ & $120+$ & 9.7 & 7.5 & 3.4 & 2.2 \\
\hline Range & - & $7.3-12.2$ & $4.3-10.7$ & $2.7-4.1$ & $1.8-2.7$ \\
\hline $\begin{array}{l}\text { Applied } \\
\text { Pressure (lbs) }\end{array}$ & 3600 & 3571 & 3668 & 3754 & 3714 \\
\hline R.S.D. & 1.9 & 3.7 & 3.3 & 1.7 & 3.3 \\
\hline
\end{tabular}

* $\left(r^{2}-0.8\right) \times 100$, see Experimental section 
time to under one minute at a concentration of two percent, an acceptable value for almost any formulation.

Changes in powder flow were not significant for low levels of disintegrant, although there might have been a general decreasing trend in linearity of the flowgram with increases in concentration of disintegrant. The mass flow rate of the powder, in all cases, decreased with increasing disintegrant concentration, although only low levels of disintegrant were used.

Examination of the disintegration times on Tables XIV-XXI, made possible the selection of five disintegrants that were effective in effecting tablet disintegration in one minute or less. The effect of these substances on other parameters such as welght, thickness, hardness and weight variation was not significant; and thus on the basts of avallability of varfous particle sizes, and powder flow characteristics, polyvinylpolypyrrolidone (P.V.P.P.) was selected for further study and subsequently optimization. It should be stressed that any of a number of other disintegrants could have been chosen for this stage of the study and that this choice is somewhat subjective. Further, it was thought that a detailed study of a single agent would be more beneficlal than a superfictal study of a number of disintegrants.

Since three particle size ranges of P.V.P.P. were avallable (0-15 microns, 50-100 microns, 50-300 microns), a study of the effect of particle size on disintegrating efficiency was undertaken. In addition, since tablet porosity seemed to affect disintegration, 
three exciplents with varying densities, particle sizes, and inherent porosity when tableted were chosen. These excipients were calcium phosphate (Emcompress) and two particle size ranges of microcrystalline cellulose (Avicel PH101, PH102). The three particle size ranges of P.V.P.P. were designated as "A" (0-15 microns), "B" (50-100 microns) and "C" (50-300 microns).

I. Evaluation of the Three Grades of P.V.P.P. (Tables XXII-XXV): Table XXII shows the flow characteristics of the three grades of P.V.P.P. In the three excipient systems. For each excipient the trend seemed similar: as particle size. increased and broadened, flow tended to improve, although this observation was more apparent with the faster flowing excipient (Emcompress) than the slower ones (Avicels).

The aspirin formulation described earlier in part $E$ of the methodology section ( $30 \%$ A.S.A., 2\% P.V.P.P.) was prepared for the three grades of P.V.P.P. in the three excipients. The formulations were compressed on a rotary tablet press, with constant die fill, and tablets were tested by methods described earlier. The results of these tests were compiled and listed in Tables XXIII-XXV.

The R.S.D. values corresponding to tablet weights seemed well within acceptable limits. Changes in tablet weights were probably due to the differing densities of the P.V.P.P. grades and the matrices. With the more-dense matrix (Emcompress), as P.V.P.P. particle size increased, there was a trend to decrease tablet weight given the same 
FLOW PROPERTIES OF. THREE MATRICES CONTAINING $2 \%(W / W)$ P.V.P.P. IN THREE PARTICLE SIZE RANGES.

EMCOMPRESS :

Mass Flow ${ }^{1}$

Linearity ${ }^{2}$

AVICEL PH-101:

Mass Flow ${ }^{1}$

Linearity ${ }^{2}$

AVICEL PH-102:

Mass Flow ${ }^{1}$

Linearity ${ }^{2}$
GRADE OF P.V.P.P.

$\begin{array}{rrrr}\text { A } & & \text { B } & \text { C } \\ 163 & & 194 & \\ 17.9 & & 18.8 & 18.4\end{array}$

22

22

24

18. 1

18.4

19.1

29

29

30

17.7

17.9

18.6

1. mean $\mathrm{gram} / \mathrm{second}$ rate for 3 trials

2. mean $\left(r^{2}-0.8\right) \times 100$ value for 3 trials 
PROPERTIES OF TABLETS MADE WITH $30 \%$ A.S.A. IN EMOOMPRESS AND $2 \%$ P.V.P.P. IN THREE PARTICLE SIZE RANGES

\begin{tabular}{lccc} 
& \multicolumn{3}{c}{ Páticle Size Grade } \\
WEIGHT (m) & $\frac{\mathrm{A}}{403}$ & $\frac{\mathrm{B}}{382}$ & $\frac{\mathrm{C}}{377}$ \\
R.S.D. & 0. & 0.9 & 1.2 \\
THICKNESS (m) & 4.3 & 4.3 & 4.2 \\
R.S.D. & 0.6 & 0.5 & 0.6 \\
HARDNESS (kg) & 5.8 & 5.3 & 4.8 \\
R.S.D. & 8.1 & 15.5 & 14.1 \\
DISINIEGRATION (sec) & 71 & 58 & 34 \\
RANGE & $45-79$ & $30-70$ & $30-40$ \\
FRIABILITY (\%) & 0.7 & 0.8 & 0.9
\end{tabular}


PROPERTIES OF TABLETS MADE WITH $30 \%$ A.S.A. IN AVICEL PH-101 AND 2\% P.V.P.P. IN THREE PARTICLE SIZE RANGES

Particle Size Grade

WEIGHT (mg)

R.S.D.

THICKNESS (mm)

R.S.D.

HARDNESS

R.S.D.

DISINIEGRATION (

RANGE

FRIABILITY (\%)
$\frac{A}{276}$

1.9

3.8

1.6

8.6

13.7

47

$30-70$

0.4
$\frac{C}{292}$

0.5

4.0

0.7

6.4

9.9

46

$25-40 \quad 30-60$

0.6

0.7 
PROPERTIES OF TABLETS MADE WITH 30\% A.S.A. IN AVICEL PH-102 AND 2\% P.V.P.P. IN THREE PARTICLE SIZE RANGES

\begin{tabular}{lccc} 
& \multicolumn{3}{c}{ Particle Size Grade } \\
WEIGFT (mg) & $\frac{\mathrm{A}}{295}$ & $\frac{\mathrm{B}}{296}$ & $\frac{\mathrm{C}}{306}$ \\
R.S.D. & 1.3 & 1.9 & 0.8 \\
THICKNESS (mm) & 4.0 & 4.1 & 4.2 \\
R.S.D. & 0.8 & 1.6 & 0.9 \\
HARDNESS (kg) & 6.5 & 6.3 & 6.0 \\
R.S.D. & 14.4 & 12.7 & 6.9 \\
DISINTEGRATION (sec) & 47 & 47 & 44 \\
RANCE & $40-55$ & $40-55$ & $43-46$ \\
FRIABILITY (\%) & 0.2 & 0.3 & 0.4
\end{tabular}


die-fill. With the less-dense matrices (Avicels), this trend seemed to be reversed.

With respect to tablet thickness, the trend was simflar to that of tablet weight, also probably due to density properties.

The tablet hardness showed a trend to decrease as particle size increased. However, this trend did not seem to be dramatic.

In almost all cases, the disintegration times were below one minute and for an aspirin tablet, this time seemed satisfactory. However, out of the three grades, the broadest particle size range, "C", gave the quickest disintegration.

There was also a slight trend to increase the percent friability as particle size increased for the P.V.P.P. However, the trend to increase the amount of compact lost due to abrasion was slight and was well below acceptable limits (workers at U.R.I. have generally recognized two percent friability as the cut-off point).

Tablet dissolution data was corrected for experimental error and plotted in Fig. 10-12. In all cases, the grade of P.V.P.P. that achieved the fastest and greatest dissolution of drug had the largest particle size range, range $C$. This effect was best seen in Fig. 12 where Emcompress was used as the matrix.

These data led to the selection of particle size grade $C$ for further study.

J. Determination of an Effective Concentration of Grade C (Fig. 12-17, Table XXVI) :

In the multivitamin formulation described earlier, the percent P.V.P.P. (grade C) was increased gradually to twenty percent (w/w). 


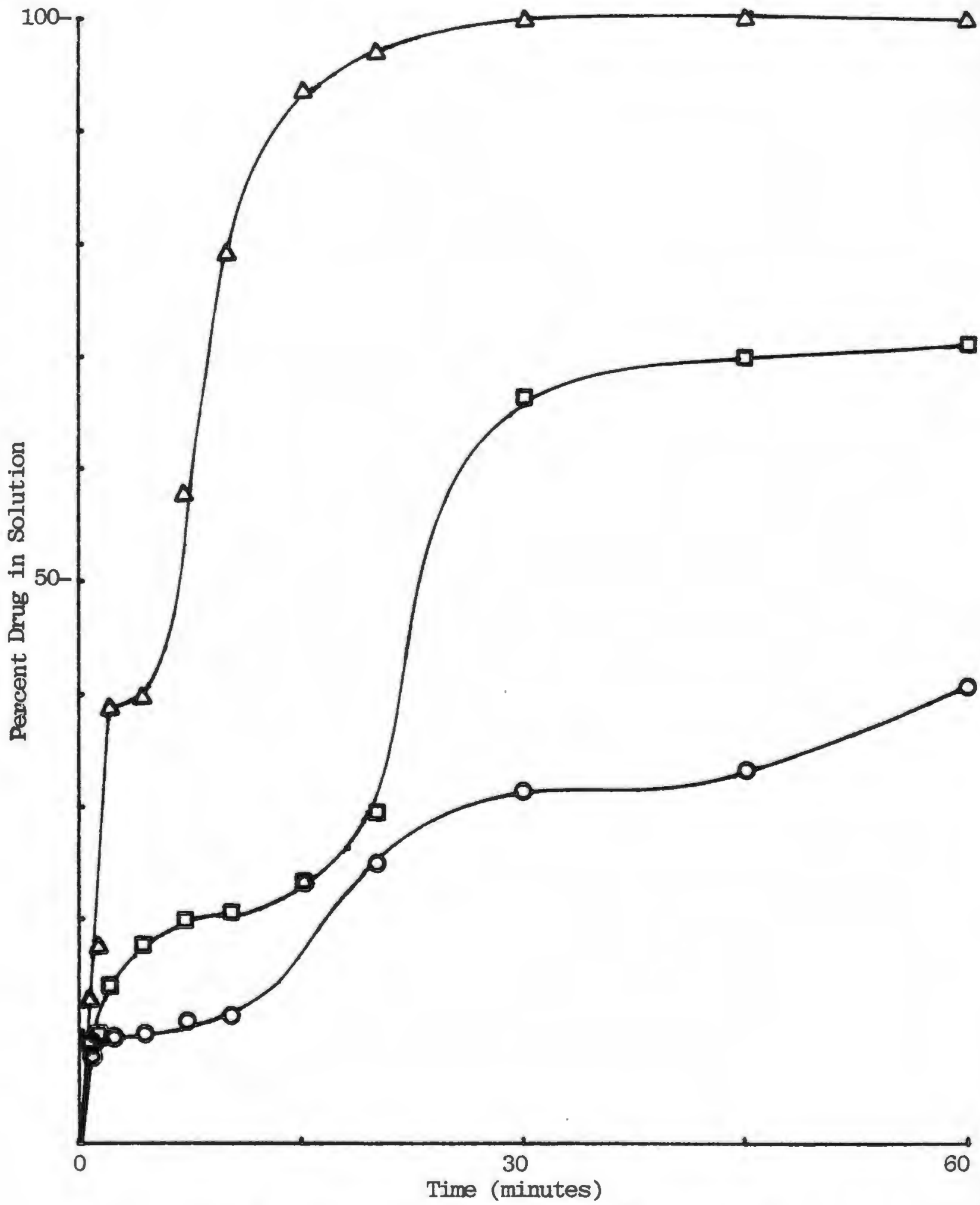

Fig. -Aspirin Dissolution Curves for the Three Grades of P.V.P.P. used in the Emcompress Formulation (30\% A.S.A., $2 \%$ P.V.P.P.).

-Grade A, -Grade B, -Grade C 
71

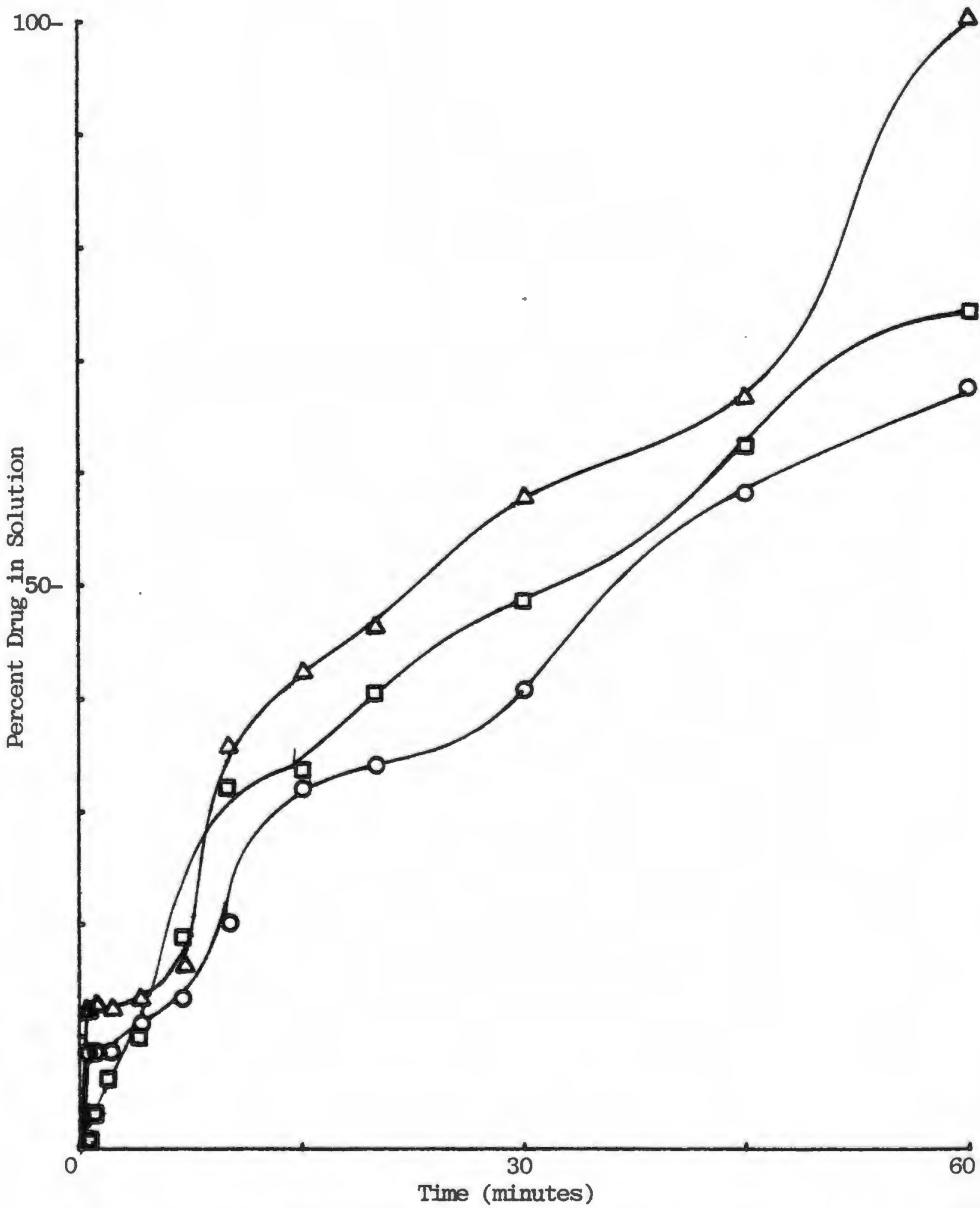

Fig. -Aspirin Dissolution Curves for the Three Grades of P.V.P.P. used in the Avicel PH-101 Formulation (30\% A.S.A., 2\% P.V.P.P.).

-Grade A, -Grade B, -Grade C 


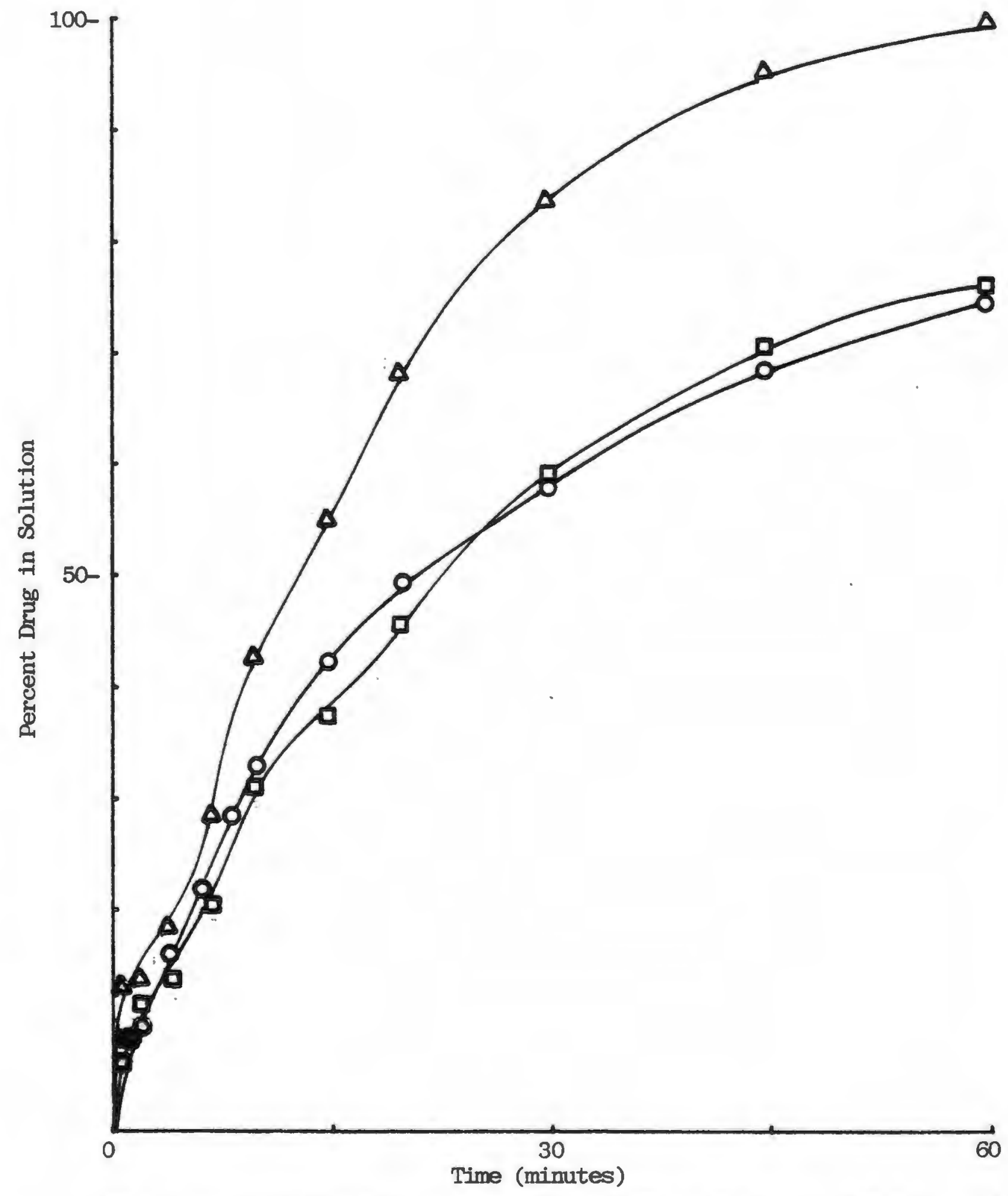

Fig. -Aspirin Dissolution Curves for the Three Grades of P.V.P.P. used in the Avicel PH-102 Formulation (30\% A.S.A., 2\% P.V.P.P.).

-Grade A, -Grade B, -Grade C 
Fig. 12 represents the change in mean tablet weight as the P.V.P.P. concentration increased. The weight generally decreased as the concentration increased, although there was a slight increase in tablet weight at the one percent level. This result may have come from the small amount of P.V.P.P. acting as a flow aid, allowing more powder to $f 111$ the die.

Tablet thickness (Fig. 13) also increased at the one percent level and then decreased gradually. Th1s may again be due to the small amount of P.V.P.P. acting as a flow aid. The thickness tended to increase at high levels of P.V.P.P. and this may have been caused by absorption of water. Table XXVI lists the flow properties of the P.V.P.P. and it can be seen that the flow did increase slightly at the one percent level and thus the flow aid theory may have some validity. The mass flow rate decreased with increasing P.V.P.P. concentration, although the linearity was minimally affected. This decrease may have been due to the fast flowing exciplent (Emcompress). It is suggested that a matrix with a slower flow rate would show more of a change in linearity than mass flow.

Fig. 14 illustrates the noticeable decrease in tablet hardness as P.V.P.P. concentration increased. This trend is mirrored in Fig. 15, the change in tablet friability as P.V.P.P. concentration increases. The amount of tablet lost due to abrasion increased as P.V.P.P. concentration increased. From the latter graph, it is obvlous that a concentration above six percent would yield unacceptable frlability values. 


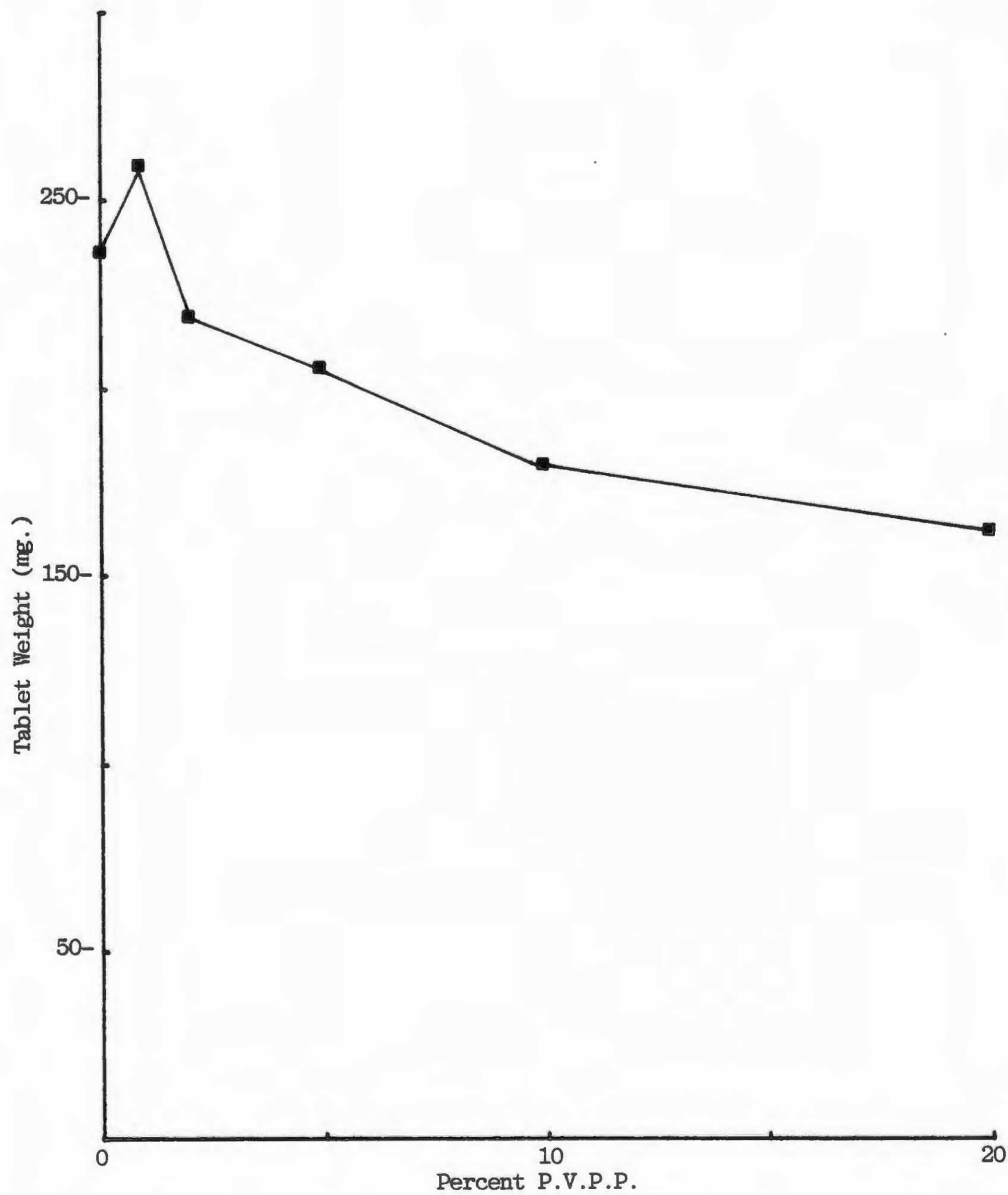

Fig. -Change in Tablet Weight as Percent P.V.P.P. Increases in a Multivitamin Formulation. 


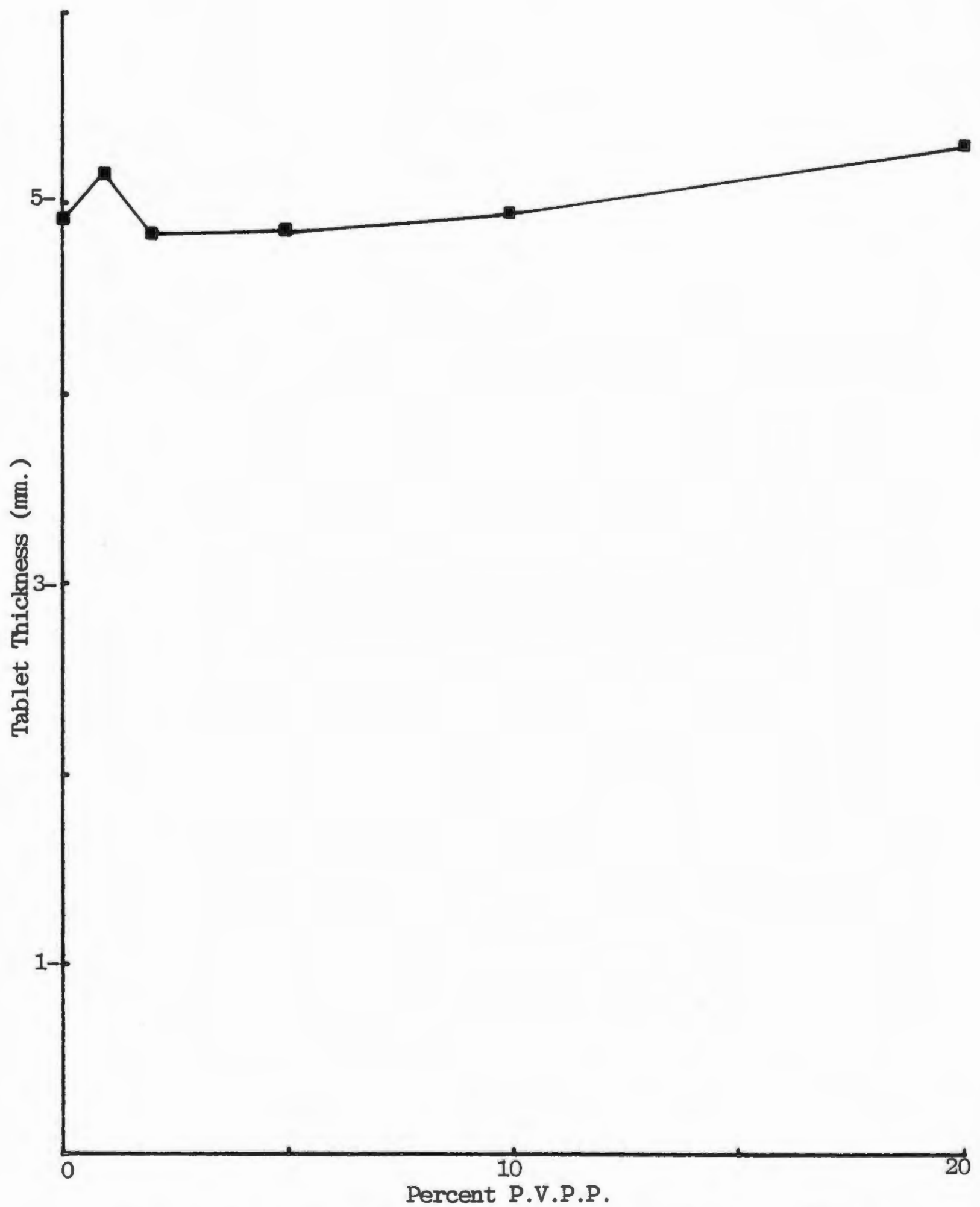

Fig. -Change in Tablet Thickness as Percent P.V.P.P. Increases in a Multivitamin Formulation. 
EFFECT OF INCREASING AMOUNTS OF P.V.P.P. ("C") ON FLOW PROPERTIES OF EMCOMPRESS

$\begin{array}{ccc}\text { \% P.V.P.P. } & \text { FLOW RATE }^{1} & \frac{\text { LINEARITY }^{2}}{\text { Control }} \\ & 227 & 18.6 \\ 2 & 227 & 19.4 \\ 5 & 203 & 19.2 \\ 10 & 199 & 18.6 \\ 20 & 177 & 18.9 \\ & 131 & 18.9\end{array}$

1. mean gram/second rate for 3 trials

2. mean $\left(r^{2}-0.8\right) \times 100$ value for 3 trials 


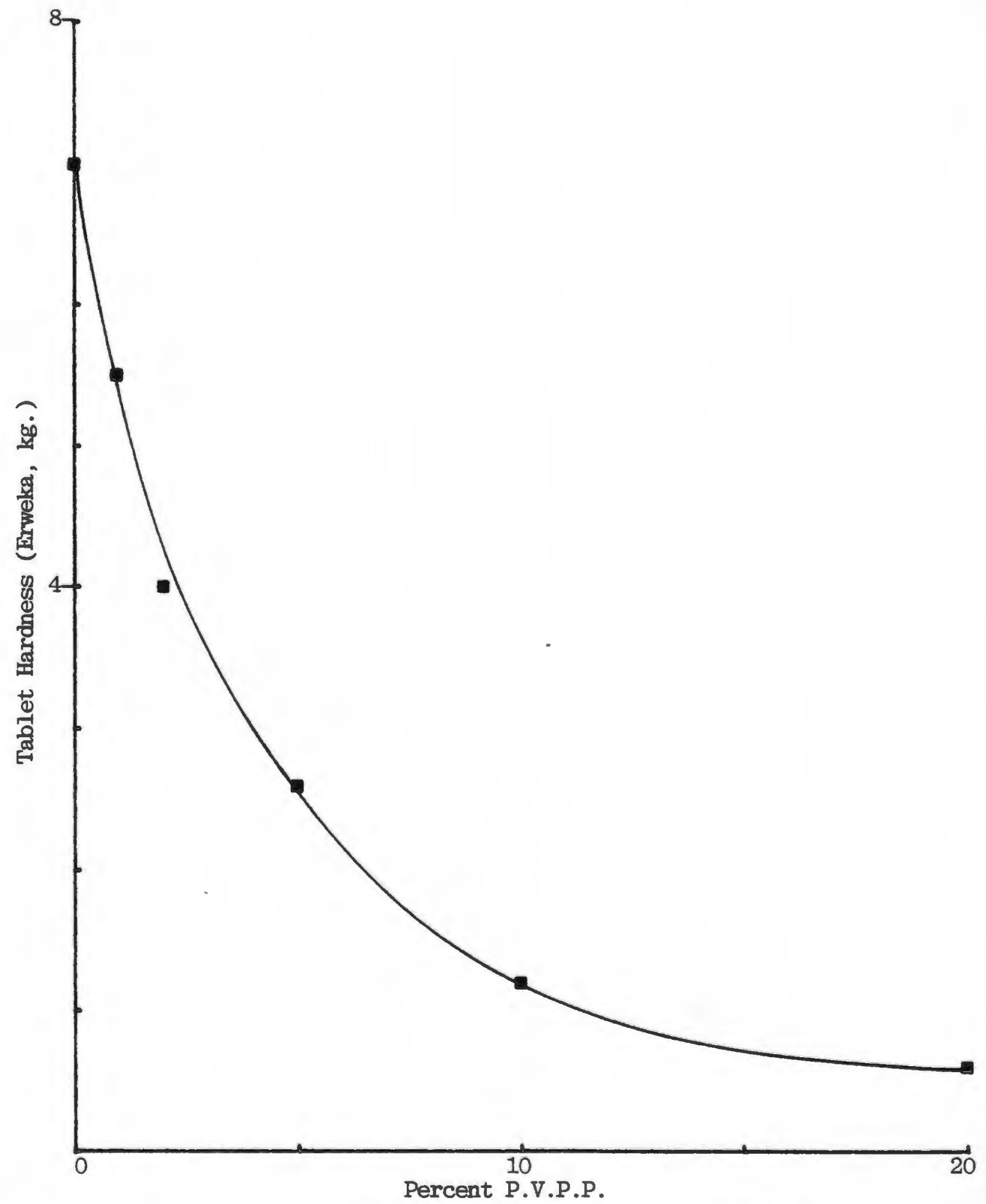

Fig. -Change in Tablet Hardness as Percent P.V.P.P. Increases in a Multivitamin Formulation. 


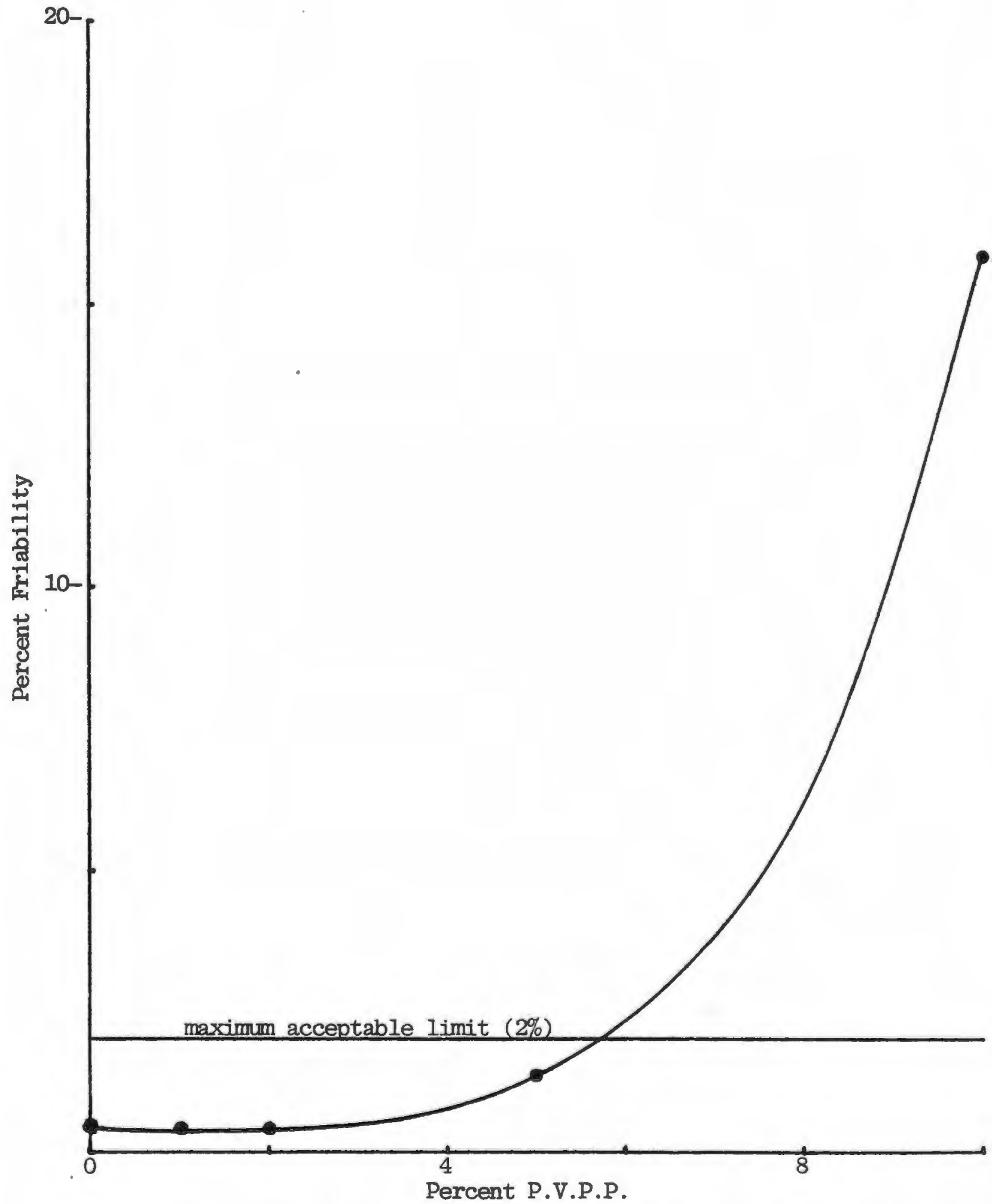

Fig. -Change in Friability as Percent P.V.P.P. Increases 
Fig. 16 shows the change in tablet disintegration as P.V.P.P. concentration increased. As expected, the disintegration time decreased as P.V.P.P. concentration increased. The effect of P.V.P.P. on reducing disintegration time seems to be limited after about five percent. Thus it seems that there would be little use in adding P.V.P.P. in concentrations above five percent; and in fact, such a course of action would increase the likelthood of adverse complications in tablet performance.

Fig. 17 shows dissolution curves for two levels of P.V.P.P. In the aspirin formulation described earlier. As one would expect, as percent P.V.P.P. increased from two to four percent, the dissolution rate increased. The extent of drug dissolution was not affected. Fig. 18 shows three replicate dissolution curves for the aspirin formulation; and as one can see, there was some variation between the three trials. However, this variation was not very great, and could be considered normal for dissolution of drugs. The time for $90 \%$ of the drug to be in solution for all three trials varied only by about three minutes.

Table XXVII 1ists tablet data for the pyridoxine formulation described in part $E$ of the methodology section. The tablet weight variation, content (assayed), and frlability were all within acceptable limits. The disintegration time was very fast, and considering ail factors, this fiormulation performed very well when tableted. Fig. 19 shows three replicate dissolution curves for pyridoxine in this formulation. In all cases, the dissolution rate 


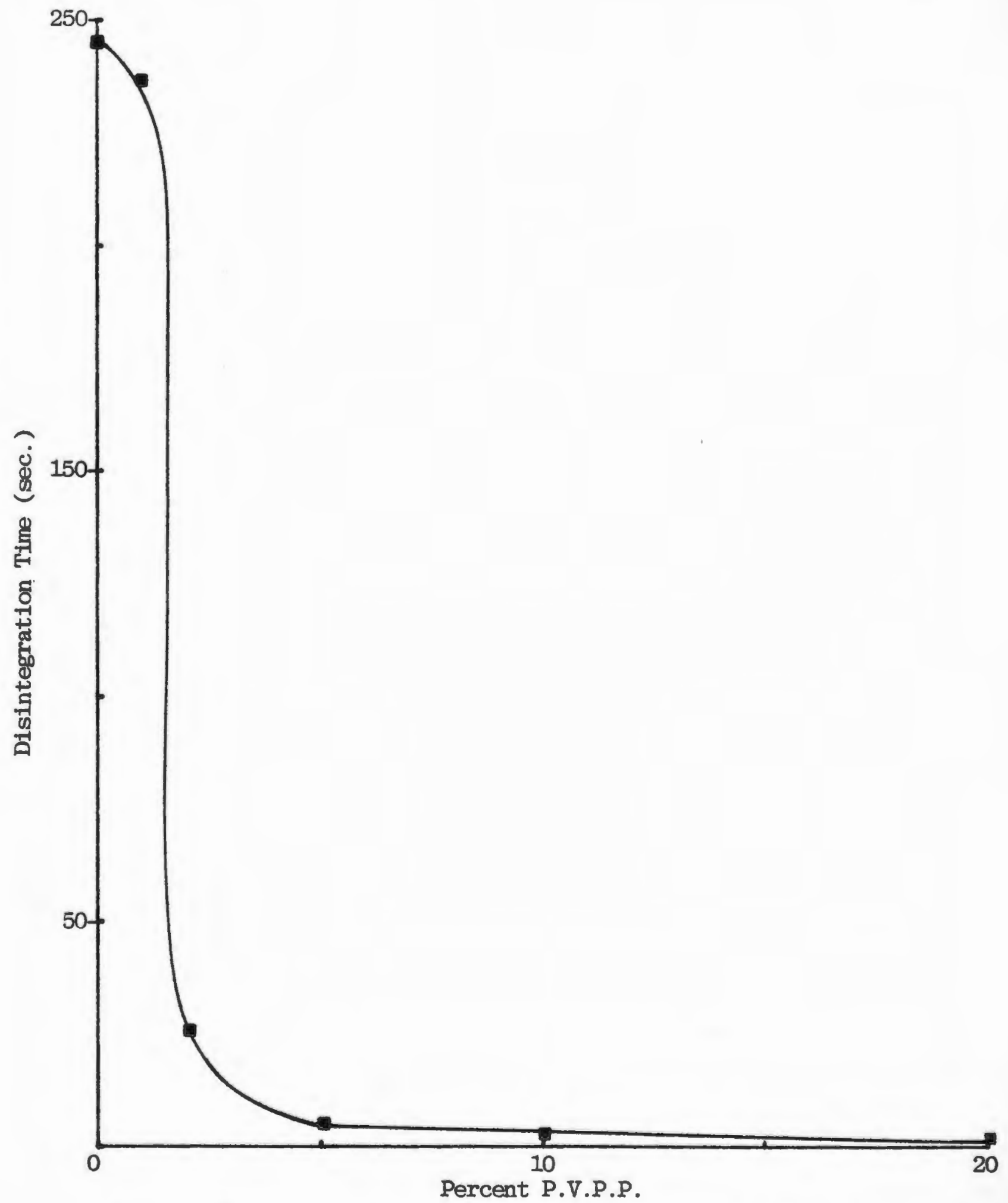

Fig. -Change in Disintegration Time as Percent P.V.P.P. Increases 
81

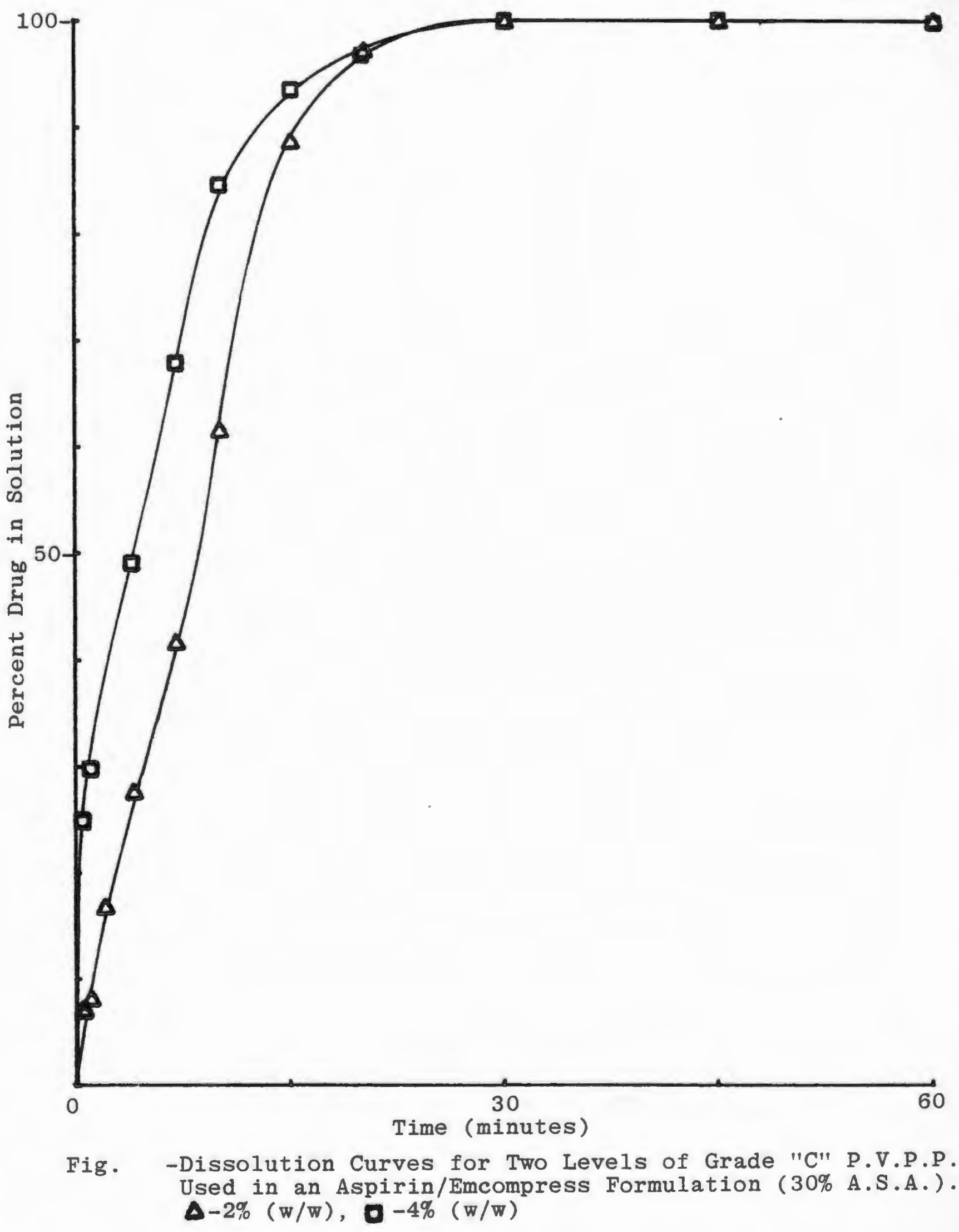




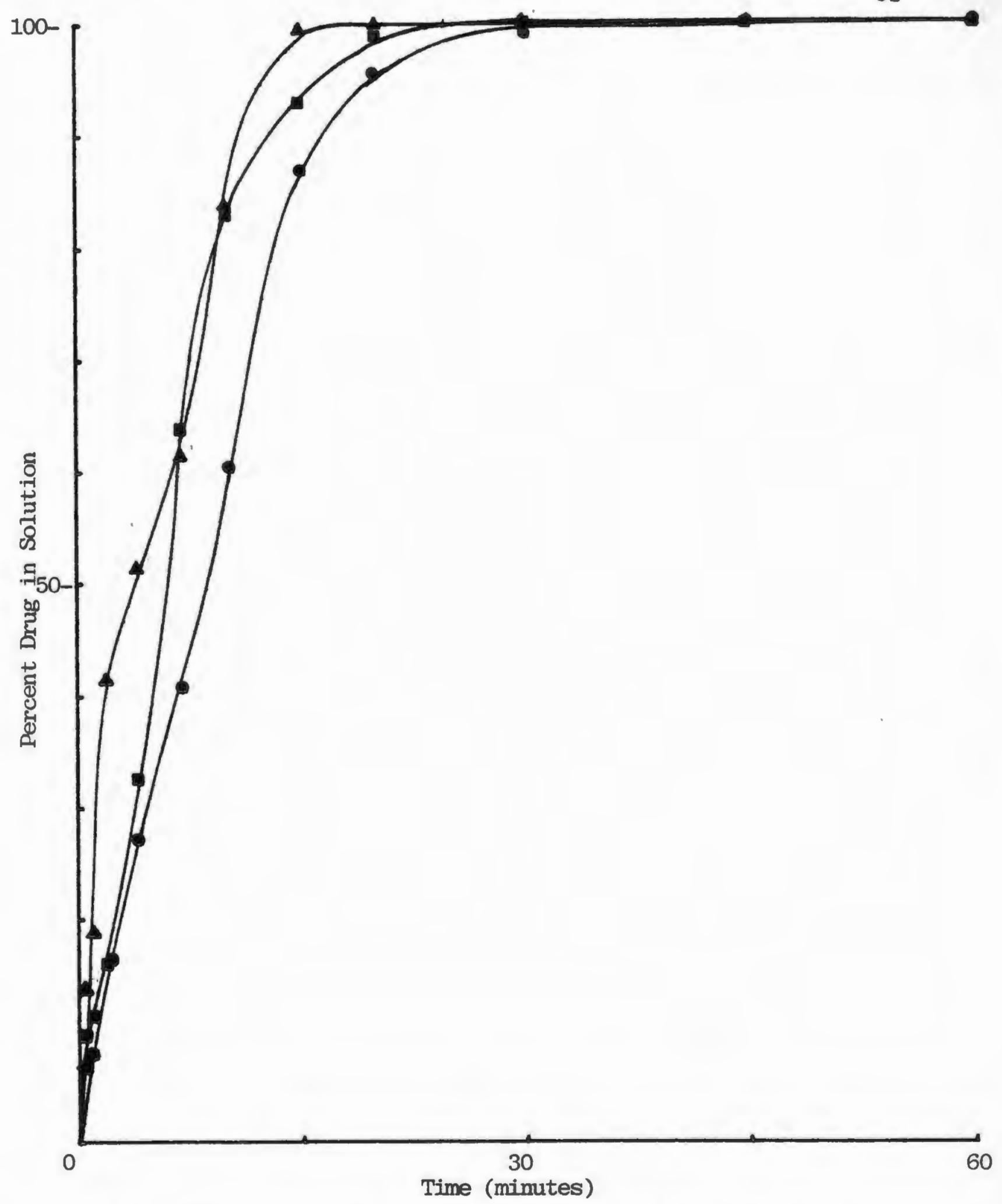

Fig. -Three Replicate Dissolution Curves for the Aspirin/Emcompress Formulation Tablets ( $30 \%$ A.S.A., 2\% Grade C P.V.P.P.). 
TABLET DATA FOR PYRIDOXINE $\left(B_{6}\right)$ FORMULATION

\begin{tabular}{|c|c|c|}
\hline & MEAN & R.S.D. \\
\hline WEIGHT (mg. ) & 100.6 & 1.7 \\
\hline THICKNESS $(\mathrm{mm} .)^{1}$ & 2.50 & 0.8 \\
\hline DISINTEGRATION $(\mathrm{sec} .)^{2}$ & 8 & $6-10$ (Range) \\
\hline FRIABILITY $(\%)^{3}$ & 0.8 & - \\
\hline CONTENT (Assayed) ${ }^{4}$ & $5.03 \mathrm{mg}$. & 0.02 \\
\hline
\end{tabular}

1. $n=10$

2. $n=6$

3. $n=20$

4. $n=30$ 


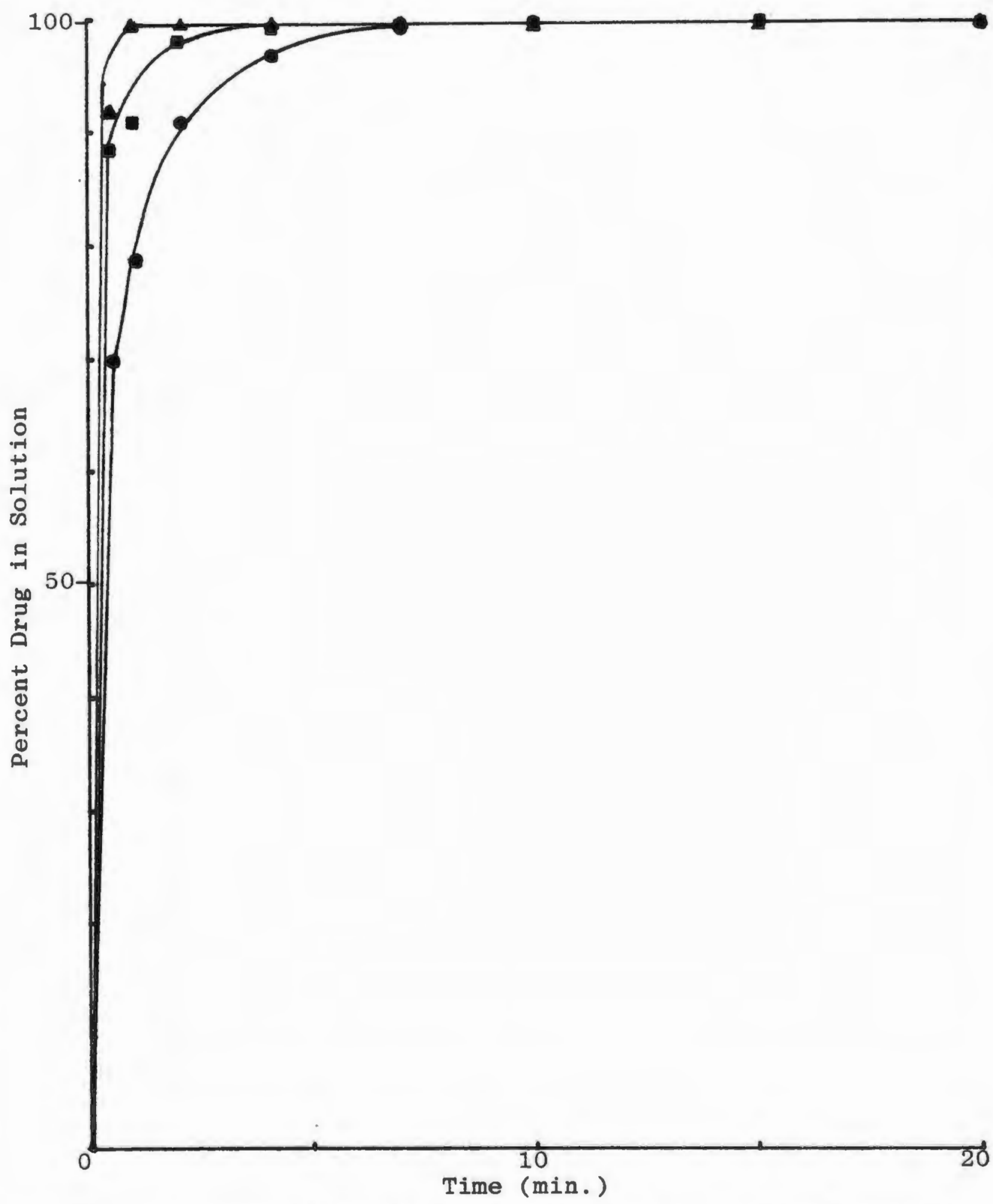

Fig. Three Dissolution Curves for Pyridoxine Formulation Tablets, ( $\%$ Pyridoxine, 2\% Grade C P.V.P.P./Fmcampress). 
was extremely fast, and all three trials produced a $90 \%$ dissolution time below three minutes. 
GENERAL CONCLUSIONS AND SUGGESTIONS FOR FURTHER WORK

In general, when a formulator processes a formulation on a piece of equipment, he must understand the limitations of that apparatus. With such knowledge, he w1ll be able to select machines, or methods, to achieve optimum efficiency of his process varlables with regard to the formulation of the pharmaceutical dosage. Since pre-compression as a granulation process (using a chilsonator/mill or by slugging/ milling) is more and more desirable for processing of water-sensitive drugs, a complete understanding of such equipment is necessary. When the chilsonator/mill was used in this study, a computerized regression showed that the speed of the compression rollers, which altered the time that the powder was exposed to compression was the most important factor in the increase in particle size of the granulation. The next most Important parameter was the rate of feed of powder flow into the compression rollers. Surprisingly, the compressional force between the rollers was the least significant factor.

The method of incorporation of a mixture of water-soluble and water-insoluble exciplents made little difference on disintegration time and other physical properties of tablets. However, when a complex pre-compression system, that contained a disintegrant, was produced by vartous methods, the disintegration times and hardness 
of the tablets varied significantly. From this study, it seemed evident that the best method of incorporation of a disintegrant into a tablet granulation would be: first, compact the water soluble Ingredients together; second, compact the insoluble ingredients together; and finally, add the disintegrant to these granules in a blender, without any compaction. This process is very close to that which many people refer to as "direct compression." Since many of the direct compression excipients marketed today are made by compaction, this finding was not altogether unexpected. Future work could usefully focus on compacting various water soluble and water insoluble drugs with various exciplents to determine whether or not solubility of excipients would be an important factor in drug release rate from pre-compressed systems. Other investigations could perhaps address tablet and granule porosity changes that occur with various methods of incorporation of both drugs and disintegrants.

The present study has shown conclusively that there are some properties of a pharmaceutical formulation that are adversely affected by large amounts of tablet disintegrants. The problems that can occur, such as poor powder flow, reduced tablet hardness and Increased tablet friability, may be avolded by using low concentrations of tablet disintegrants. A number of disintegrants, thought to be effective at concentrations of five percent or greater, have been shown to induce disintegration of tablets are concentrations as low as one or two percent. Another possible topic for future research might be the study of the effects of low concentrations of disintegrants in wet granulation systems. 
When relative disintegrating efficiency has been established and one specific tablet disintegrant has been chosen, the formulator should not stop the optimization process there. The work reported in this thesis has shown that altering particle size of a tablet disintegrant can effect great changes in disintegration time as well as both the rate and extent of drug dissolution. Other properties such as powder flow, tablet hardness and tablet frlability were also affected by such changes and thus should be considered. In this connection, another area which would merit further study would be the evaluation of the effect of varying particle size of other disintegrants. Further, it would be interesting to study a wider range of drugs and thetr subsequent release from tablets made with these disintegrants.

Although it may seem that the selection of a formulation containing a specific tablet disintegrant is an extremely long, drawn-out process, it does not necessarily have to be that way. Knowing the advantages and the Iimitations of the varfou processes and equipment avaflable to the formulator, he can make many reasonable assumptions based on this information, and eliminate many of the preliminary evaluation steps. This study has tried to shed light on some of the evaluation processes and Ifmitations assoclated with them. When one selects any tablet disintegrant, he should strive to optimize all aspects of the disintegrant in the given pharmaceutical formulation. He may achieve this end by altering method of incorporation, particle size, exciplent solubility, compression force, disintegrant concentration and other factors. 
Every pharmaceutical system is unique, and the optimization process must therefore be unique to any given system. Certain procedures that will apply for one system may not be applicable to another. Although a study of all of these procedures and applications would be overwhelming, the results reported in this thesis show that a rational approach to formulation is indeed practicable. The traditional intuitive approach which is still so widely used in the formulation of pharmaceutical products can in many areas of tablet formulation and processing quite properly be regarded as obsolescent. It is hoped that with an understanding of the disintegration process and the variables which affect it, optimization of a tablet disintegrant in a given pharmaceutical system will become increasingly common within the pharmaceutical industry. 


\section{REFERENCES}

1. J. M. Richards, U. S. Patent 非16,107 (1879).

2. W. Lowenthal, J. Pharm. Sc1., 61: 1695 (1972).

3. J. Cooper, J. E. Rees, J. Pharm. Sc1., 61: 1511 (1972).

4. R. R. Levine, "Pharmacology: Drug Actions and Reactions," Ist Edition, Little, Brown and Co., 1973, p. 83.

5. J. R. Halebian, F. W. Goodhart, J. Pharm. Sc1,, 64: 1085 (1976).

6. W. C. Gunsel, J. L. Kanlg, in "The Theory and Practice of Industrial Pharmacy," 2nd Edition, Lea and Febiger, 1976, Philadelphia p. 297.

7. K. Marshall, in "Modern Pharmaceutics" (G. S. Banker and C. T. Rhodes, Eds.), Marcel Decker, Inc., 1979, New York pp. 336-408.

8. E. L. Parrott, "Phsrmaceutical Technology," Burgess Publishing Co., 1970, Minneapolis, p. 82 .

9. H. C. Ansel, "Introduction to Pharmaceutical Dosage Forms," Lea and Febiger, 1972, Philadelphia, p. 297.

10. "The National Formulary," XIV Edition, Mack Publishing Co., Easton, Pennsylvania, 1975, p. 941.

11. N. R. Bohidar, F. A. Restaino, and J. B. Schwartz, J. Pharm. Sc1., $64: 966$ (1975).

12. B. Hoener and L. Z. Benet, in "Modern Pharmaceut 1 cs," (G. S. Banker and C. T. Rhodes, Eds.), Marcel Decker, Inc., 1979, New York, Pp. 158-162. 
13. J. B. Schwartz, Ibid., Pp. 711-734.

14. K. Marsha11, D. S1xsmith, Drug Develop. Comm., 1: 51 (1974).

15. F. Fuchs, Arch. Pharm., 303: 471 (1970).

16. K. A. Kahn, C. T. Rhodes, J. Pharm. Pharmacol., 23: 261A (1971).

17. W. Feinstein, J. Bartilucci, J. Pharm. Sci., 55: 331 (1966).

18. W. Lowenthal, J. A. Wood, Ibid., 62: 287 (1973).

19. R. Huttenrauch, Pharmazie, 26: 293 (1971).

20. A. M. Khalek, A. A. Kader, J. Pharm. Sc1., UAR 5: 114 (1964).

21. E. E. Bozunov, S. M. Shevchenko, Farmatisya (Moskow), 18: 20 (1969), through Chem. Abstr. 71: 33385y (1969).

22. N. R. Patel, R. E. Hopponen, J. Pharm. Sc1., 55: 1065 (1966).

23. H. Matsumaru, Yakigaku Zasshi, 78: 1198 (1958), through Chem. Abstr., 5.3: 3602a (1959).

24. L. Krowczynsk1, R. Kolarsk1, and K. Swoboda, Acta. Po1. Pharm., 25: 443 (1968).

25. F. Jaminet, L. Delattre, and G. Godfrlaux, J. Pharm. Belg., 22: 95 (1967).

26. H. V. Czetsch-Lindenwald, F. El Khawes, and R. Tawashi, J. Soc. Cosmet. Chem., 16: 251 (1965).

27. N. J. Van Abbe and J. T. Rees, J. Amer. Pharm. Assoc., Sc1. Ed., $47: 487$ (1958).

28. W. J. Husa, Ibid., $17: 38$ (1928).

29. I. K. McKee, and W. Herbst (to National Starch and Chemical Corp.), U. S. Patent \#3,034,911 (1962).

30. F. Jaminet, J. Pharm. Belg., 19: 144 (1964). 
31. H. Berry and C. Ridout, J. Pharm. Pharmacol., 2: 619 (1950).

32. M. H. Rubinstein, D. M. Bodey, J. Pharm. Pharmacol., 26: 104P (1974).

33. E. Shotten, G. S. Leonard, Ibid., 24: 798 (1972).

34. R. A. Kahn, D. I. Rooke, Manuf. Chemist \& Aerosol News, I (1976).

35. J. B.Schwartz, E. T. Martin, and E. J. Dehner, J. Pharm. Sc1., 64: 966 (1975).

36. N. R. Bohidar, F. A. Restaino, and J. B. Schwartz, J. Pharm. Sc1., 64: 966 (1975).

37. "Problem Solver," FMC Corporation, Philadelphia, pp. III-10.

38. W. Lowenthal, J. Pharm. Sc1., 61: 1705 (1972).

39. J. B. Schwartz; J. R. Flamholz, R. H. Press, J. Pharm. Sc1., 62: 1165 (1973).

40. Ibid., 62: 1518 (1973).

41. N. R. Bohidar, F. A. Restaino and J. B. Schwartz, Drug Develop. and Indust. Pharm., 5(2), 175 (1979).

42. S. S. Kornblum, S. B. Stoopack, J. Pharm. Sc1., 62: I (1972).

43. A. M. Sakr, A. A. Kassem, Mfg. Chem., Aerosol News, 43: 37 (1972).

44. J. B. Schwartz and J. A. Zelinskie, Drug Develop. and Indust. Pharm., 4(5), 463 (1978).

45. W. C. Gunsel and J. L. Ranig, in "The Theory and Practice of Industrial Pharmacy," 2nd Edition, Lea and Febiger, 1976, Philadelphia, pp. 336, 337.

46. H. K. Malinowski, Ph.D. Dissertation, Philadelphia College of Pharmacy, 1973. 
47. K. Marshal1, in "Modern Pharmaceutics," (G. S. Banker and C. T. Rhodes, Eds.) Marcel Decker, Inc., New York, 1979, p. 399.

48. H. Ravarana and H. M. Burlage, Amer. Prof. Pharm., 21, 348, 383, 450,473 (1955).

49. T. Higuch1, A. N. Rao, I. W. Busse, and J. V. Swintosky, J. Amer. Pharm. Assoc., Sc1. Ed., 42, 194 (1953).

50. E. P. Stevens and J. W. Wallace, in "Problem Solver," FMC Corporation, Philadelphia, 1977.

51. H. Sprengler and J. Jud, Pharm. Acta. Helv., 12, 337 (1937).

52. K. Kolarski and L. Krowczynsk1, Acta. Po1. Pharm., 27, 477 (1970).

53. V. C. Krebs, An. Fac. Quim. Farm., Univ. Chile, 11, 204 (1959), through Chem. Abstr., 54, $25575 f$ (1960).

54. J. T. Ingram and W. Lowenthal, J. Pharm. Sc1., 55, 614 (1966).

55. A. D. Nair and V. N. Bhatia, J. Amer. Pharm. Assoc., Sc1. Ed., $46,131(1957)$

56. H. Burlinson and C. Pickering, J. Pharm. Pharmaco1., 2, 630 (1950).

57. H. M. Gross and C. H. Becker, J. Amer. Pharm. Assoc., Sc1. Ed., 41,157 (1952)

58. H. Gibian, et al., Acta Physiologica Latinoamericana, 18, 323 (1968).

59. J. G. Reinhold, et al., Amer. Jour. Med. Sci., 210, 141 (1945).

60. J. G. Wagner in "Blopharmaceutics: Gastrointestinal Absorption Aspects," Pharmacokinetic u. Arzneimitteldosierung, Kolloquium, Borstel, 1962 .

61. A. J. Glasko, et al., Clinical Pharmacy and Therapeutics, 9, 472 (1967). 
62. K. Kakem1, et al., Symposium on Drug Absorpt1on, Metabolism and Excretion, Paper B-IV, Preprints of Papers (Scientific Section of the American Pharmaceut1cal Association), Las Vegas, (1962).

63. R. R. Levine and E. W. Pelikan, Annu. Rev. Pharmacol., 4: 69 (1964).

64. The American Heritage Dictionary, William Morr1s, Ed., Dell Publishing Co., Inc., New York, 1979.

65. Remington's Pharmaceutical Sclences, 15th Edition, Mack Publishing Co., Easton, Pennsylvania.

66. Sprowls American Pharmacy, 7th Edition, 1974, J. B. Lippincott Co., Philadelphia.

67. W. G. Gunsel and J. L. Kanig in "The Theory and Practice of Industrial Pharmacy," 2nd Edition, 1976, Lea and Febiger, Philadelphia.

68. H. A. Berry and C. W. Ridout, J. Pharm. Pharmacol., 2, 619 (1950).

69. R. A. Ramsay, Ibld., 10, 145t (1958).

70. H. Nogami, J. Hasegowa, M. Miyamoto, Chem. Pharm. Bull., 57, 279 (1967).

71. W. Lowenthal, R. A. Buruss, J. Pharm. Sc1., 60, 1325 (1971).

72. E. L. Rnoechel, C. C. Sperry, and C. J. Lintner, J. Pharm. Sc1., $56,116(1.967)$.

73. T. Higuch1, L. N. Elowe, L. W. Busse, J. Amer. Pharm. Assoc., Sc1. Ed., 43, 685 (1954).

74. J. B. Schwartz, in "Modern Pharmaceut1cs," (G. S. Banker and C. T. Rhodes, Eds.), Marcel Decker, Inc., New York, $197,$.

75. K. Marsha11, in "The Physics of Tablet Compression," Presented at the 12th Annual Arden House Conference, Feb. 2, 1977. 
76. H. Sprengler and E. Shenker, Pharm. Acta. Helv., 12, 337 (1937).

77. H. Sprengler and J. Jud, Ib1d., 18, 565 (1943).

78. W. Feinstein and A. J. Bartillucc1, J. Pharm. Sc1., 55, 332 (1966).

79. T. A. Fakouk1, N. F. Billups and R. W. Sager, J. Pharm. Sc1., $52,700(1963)$

80. H. Delonca, A. Puech, M. Delonca and N. V. Do1, J. Pharm. Belg., $21,67(1966)$.

81. E. M. Rudnic, R. Chilamkurt1, and C. T. Rhodes, Drug Develop. and Indust. Pharm., May (3), (1980).

82. E. M. Rudnic, R. Chilamkurt1, and C. T. Rhodes, Ibid., May (3), (1980)

83. N. R. Patel, R. E. Hopponen, J. Pharm. Sc1., 55, 1065 (1966).

84. D. E. Cadwallader, in "Blopharmaceutics and Drug Interactions," 2nd Edition, Rocom Press, New Jersey, 1974, pp. 58-64.

85. The National Formulary, XIV Edition, Mack Publishing Co,, Easton, Pennsylvanta, 1975, p. 978.

86. L. L. Raplan, J. Pharm. Sc1., 53, 447 (1964).

87. G. Gold, R. N. Duvall, B. T. Palermo, J. Pharm. Sc1., 57, 667 (1968).

88. R. N. Duvall, in "Methods of Evaluating and Factors Affecting the flow of Pharmaceutical Powders," Presented at the Reglonal IPT Meeting, Academy of Pharmaceutical Sciences, Philadelphia, Pennsylvania, October 16, 1970.

89. R. P. Jordan, C. T. Rhodes, Drug Develop. and Indust. Pharm., 5,151 (1979) 
90. M. J. Stokosa, "Pharmaceut1cal Calculat1ons," 6th Ed1t1on, Lea and Febiger, Philadelphia, 1974.

91. G. L. Jenkins, A. M. Knevel, and F. E. DIGang1, "Quant Itat Ive Pharmaceutical Chemistry," 6th Edition, McGraw-Hill Book Co., New York, 1967.

92. S. C. Cho1, "Introductory Applied Statistics in Sclence," Prentice Hall Co., New Jersey, 1978.

93. G. W. Snedecor and W. G. Cochran, "Stat1st1cal Methods," 6th Ed1tion, Iowa State University Press, Ames, Iowa, 1978.

94. Lange's Handbook of Chemistry, N. A. Lange, Ed., Revised LOth Edition, McGraw-Hill Book Co., New York, 1969.

95. R. T. Morrison and R. N. Boyd, "Organic Chemistry," 3rd Edition, Allyn and Bacon, Inc., Boston, 1973.

96. Handbook of Chemistry and Physics (R. C. Weast, Editor), 52nd Edition, Chemical Rubber Co., Cleveland, OhIo, 1972..

97. The United States Pharmacopeia, XIX, Unfted States Pharmacopela Convention, Rockville, Maryland, 1975. 